TITLE:

\title{
Performance improvement of the PD-based bilateral teleoperators with time delay by introducing relative D-control
}

\section{$\operatorname{AUTHOR}(S)$ :}

Imaida, Takashi; Senda, Kei

\section{CITATION:}

Imaida, Takashi .... et al]. Performance improvement of the PD-based bilateral teleoperators with time delay by introducing relative D-control. Advanced Robotics 2015, 29(6): 385-400

ISSUE DATE:

2015-03-23

URL:

http://hdl.handle.net/2433/198815

\section{RIGHT:}

This is an Accepted Manuscript of an article published by Taylor \& Francis in Advanced Robotics on 23 Mar 2015, available online: http://www.tandfonline.com/10.1080/01691864.2014.993797; ; 許諾条件により本文ファイルは201603-23に公開;; This is not the published version. Please cite only the published version.; この論文は出版社版でありませ ん。引用の際には出版社版をご確認ご利用ください。 


\title{
Performance improvement of the PD-based bilateral teleoperators with time delay by introducing relative D-control
}

\author{
Takashi Imaida, \\ Kei Senda \\ Department of Aeronautics and Astronautics, Graduate School of Engineering, \\ Kyoto University, Kyoto 615-8530 Japan
}

\begin{abstract}
In a force-reflecting bilateral teleoperator with a time delay, teleoperator stability is a serious problem. We have studied a bilateral teleoperator system with a time delay. We obtained stable conditions using proportional derivative based (PD-based) control law. In this paper, PD-based control law is further studied. First, we study a PD control law with relative damping gain and its stabilizing effect that previously has not been studied quantitatively. A stable condition is derived with this PD-based controller with relative damping gain. Next, teleoperator performance by the PD control law with relative damping is evaluated and compared to PD control laws with only grounded damping using transparency analysis with a hybrid matrix. We showed that, the performance of the PD-based controller can be improved by introducing relative damping gain into the controller. As a controller design example, numerical simulations and 1-DOF experiments were conducted. Finally, peg-in-hole experiments and performance evaluations in realistic multi-DOF environments were conducted to demonstrate performance improvements by introducing the relative damping. A controller design that guarantees both stability and performance was achieved by iterating stable gain setting and performance evaluation.
\end{abstract}

keywords: Bilateral control, Passivity, Teleoperation, Time delay

\section{INTRODUCTION}

A bilateral teleoperator provides important force information from a remote environment to an operator. When there is transmission time delay, stability is a major problem with conventional bilateral control methods such as a symmetric position servos or a force-reflecting servos [23]. Anderson and Spong [1] proposed a bilateral control law using scattering theory and maintained stability in spite of communication delays. Niemeyer and Slotine [12] [13] [14] also studied this problem. Besides the above well-known approaches, there are several other approaches. Leung et al. [9] proposed a bilateral controller for time delays based on the $\mathrm{H} \infty$-optimal control and $\mu$-synthesis framework. Seo, et al. [22] proposed a bilateral teleoperator with an energy-bounding algorithm. Oboe, et al. [19], Nuno, et al. [15] and Lee, et al. 
[8] dealt with this problem by using a proportional derivative (PD) controller. We focused on PD controllers [5]. The PD bilateral controller has two designs for adding derivative controller gain, grounded damping, and relative damping. The term "relative damping" means the damping force is proportional to the difference between master velocity and slave velocity. "Grounded damping" means the damping force is proportional to the absolute arm velocity. In reference to [5], we derived the stable PD controller conditions with grounded damping. However, the characteristics of grounded damping gain and relative damping gain were not studied. Lee, et al [8] studied the PD controller. In their analysis they separately discussed the passivity of a proportional gain - grounded damping gain system and the passivity of a relative damping gain system. They achieved a sufficiently stable teleoperator. However, they did not explain the point how the two types of damping gain effect each other, stability and performance. Nuno, et al [15] [16] [17] [18] studied PD controllers. In their research, they stabilized a teleoperator system with a grounded damper gain and relative damper gain. At the end of their study[16], they noticed that relative damping gain had a stabilizing effect, but their control law was only stabilized by a grounded damping gain, not with a relative damping gain. The PD controller with only grounded damping and the PD controller with grounded and relative damping have been commonly used in delayed bilateral master-slave applications [6] [21], but a comparison of these two controllers has not been conducted. The effect of the addition of relative damping has not been clarified.

This paper studies the teleoperator stability of a PD controller with both types of damping. A stability condition is derived. We will show that the introduction of relative damping maintains the stability of a system with attenuated grounded damping and improves performance. The teleoperator performance is studied by a transparency analysis using hybrid matrices and simulations. A controller design procedure that guarantees both stability and performance is proposed. The stability, performance evaluation method, controller design method and controller performance are evaluated with 1-DOF numerical simulations. Finally, peg-in-hole experiments are conducted to evaluate the validity of these methods in a realistic multi-DOF condition.

In this work, we assume the delay is constant, the delay value is known, and the delay from master to slave and the delay from slave master are equal. The stability under other delay conditions are discussed in Appendix. D.

\section{DYNAMICS, STABILITY AND PERFORMANCE EVAL- UATION OF THE TELEOPERATOR SYSTEM}

\subsection{Dynamics of the teleoperator system}

We studied the stability of a single degree of freedom teleoperation system composed of a pair of manipulators with a time delay as shown in Fig. 1. The springs and dampers in the "control" area of the dashed line box in Fig. 1 are not the real mechanisms. They are mechanical expressions of the 
control law. The dynamics of master and slave arms can be formulated as follows:

$$
\begin{gathered}
\tau_{m}+f_{m}=m_{m} \ddot{x}_{m}+b_{m} \dot{x}_{m} \\
\tau_{s}-f_{s}=m_{s} \ddot{x}_{s}+b_{s} \dot{x}_{s}
\end{gathered}
$$

where $x_{m}$ and $x_{s}$ denote the respective positions of the master and slave arms, $\tau_{m}$ and $\tau_{s}$ are the actuator driving forces, and $b_{m}$ and $b_{s}$ represent the viscous coefficients of the driving mechanism. $f_{m}$ is the force the operator applies to the master arm, and $f_{s}$ is the force the slave arm exerts on the environment.

The generalized mass-dashpot-spring models that are used to represent the operator and the task are

$$
\begin{gathered}
\tau_{o p}=m_{o p} \ddot{x}_{m}+b_{o p} \dot{x}_{m}+c_{o p} x_{m}+f_{m} \\
f_{s}=m_{w} \ddot{x}_{s}+b_{w} \dot{x}_{s}+c_{w} x_{s}
\end{gathered}
$$

where $\tau_{o p}$ is the force generated by the operator's muscles. In the preceding equations, $m, b$, and $c$ are the inertia, damping, and stiffness parameters. Subscript op is the operator and $w$ is the task.

In this paper, the development of an analytical framework is complemented by the modeling of an actual teleoperator system. The modeling approach transforms the teleoperator system model into an electrical circuit. The teleoperator system can be replaced by an electric circuit, see Fig. 2. Replacing velocity and force in physical systems with current and voltage in circuits, the dynamic characteristics of the master and the slave arm, the operator, and the environment are represented by impedance $Z_{m}, Z_{s}, Z_{o p}$, and $Z_{e}$, respectively. The $V_{m}, V_{s}, V_{o p}, I_{m}$, and $I_{s}$ correspond to $f_{m}, f_{s}, f_{o p}, \dot{x}_{m}$, and $\dot{x}_{s}$, respectively. The $U_{m}$ and $U_{s}$ are the actuator drive forces $\tau_{m}$ and $\tau_{s}$.

The $Z_{m}, Z_{s}, Z_{o p}$, and $Z_{e}$ are

$$
\begin{gathered}
Z_{m}=\frac{m_{m} s^{2}+b_{m} s}{s} \\
Z_{s}=\frac{m_{s} s^{2}+b_{s} s}{s} \\
Z_{o p}=\frac{m_{o p} s^{2}+b_{o p} s+c_{o p}}{s} \\
Z_{e}=\frac{m_{w} s^{2}+b_{w} s+c_{w}}{s} .
\end{gathered}
$$

Using these electric circuit representations, the teleoperator system is expressed by

$$
\left[\begin{array}{l}
V_{m} \\
V_{s}
\end{array}\right]=\left[\begin{array}{ll}
z_{11} & z_{12} \\
z_{21} & z_{22}
\end{array}\right]\left[\begin{array}{c}
I_{m} \\
-I_{s}
\end{array}\right]
$$

where $\boldsymbol{Z}=\left[z_{i j}\right]$ is the impedance matrix of the teleoperator [20]. 


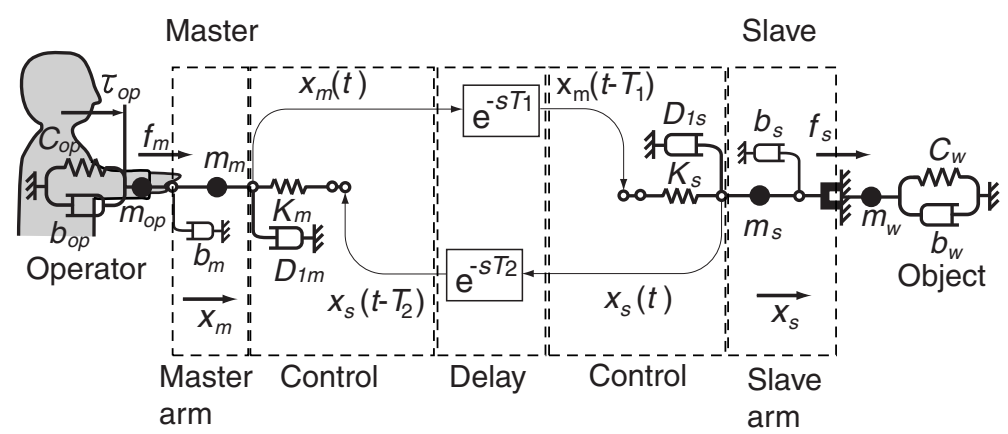

Figure 1: Bilateral master slave system with PD controller with only grounded damping gain.

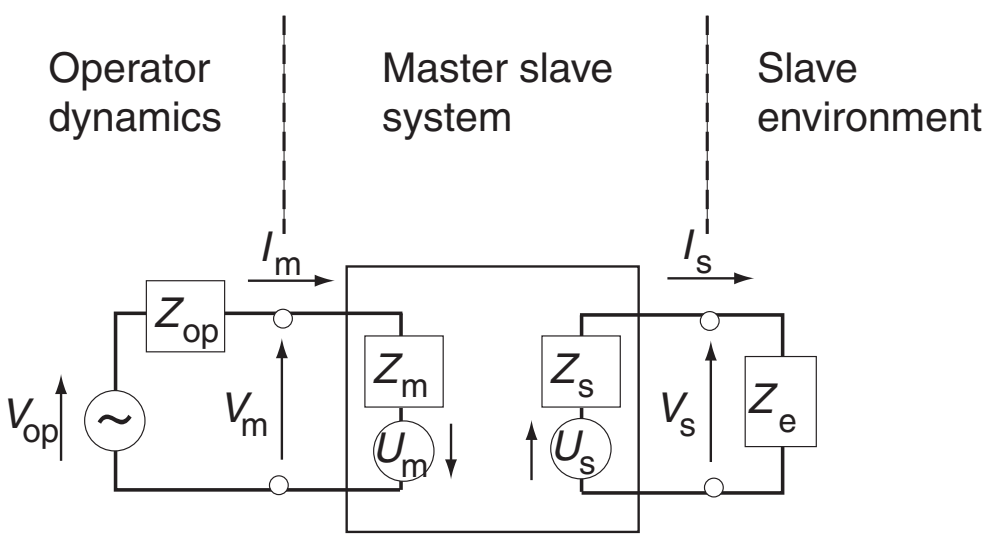

Figure 2: Electrical circuit expression of master-slave system, operator and environment.

\subsection{Stability of PD-based bilateral controller with grounded damping}

We derive bilateral PD controller stability with only grounded damping. The PD controller is expressed by the following equations:

$$
\begin{gathered}
\tau_{m}=-K_{m}\left(x_{m}(t)-x_{s}\left(t-T_{2}\right)\right)-D_{1 m} \dot{x}_{m} \\
\tau_{s}=K_{s}\left(x_{m}\left(t-T_{1}\right)-x_{s}(t)\right)-D_{1 s} \dot{x}_{s}
\end{gathered}
$$

where $K_{m}$ and $K_{s}$ are position gains and $D_{1 m}$ and $D_{1 s}$ are grounded damping gains. $T_{1}$ and $T_{2}$ are time delays from the master to the slave and from the slave to the master, respectively. The physical interpretation of this controller is shown in Fig. 1.

The impedance matrix of the teleoperator is as follows [3]:

$$
\boldsymbol{Z}=\left[\begin{array}{cc}
m_{m} s+b_{m}+D_{1 m}+\frac{K m}{s} & K_{m} e^{-s T_{2} / s} \\
K_{s} e^{-s T_{1}} / s & m_{s} s+b_{s}+D_{1 s}+\frac{K s}{s}
\end{array}\right]
$$

We derived stability for any passive terminations by applying Llewellyn's stability criteria [2] [10] to (12). The teleoperator is stable for all passive terminations if the following conditions are satisfied for all frequencies:

$$
D_{1 m}+b_{m} \geq 0
$$


Master

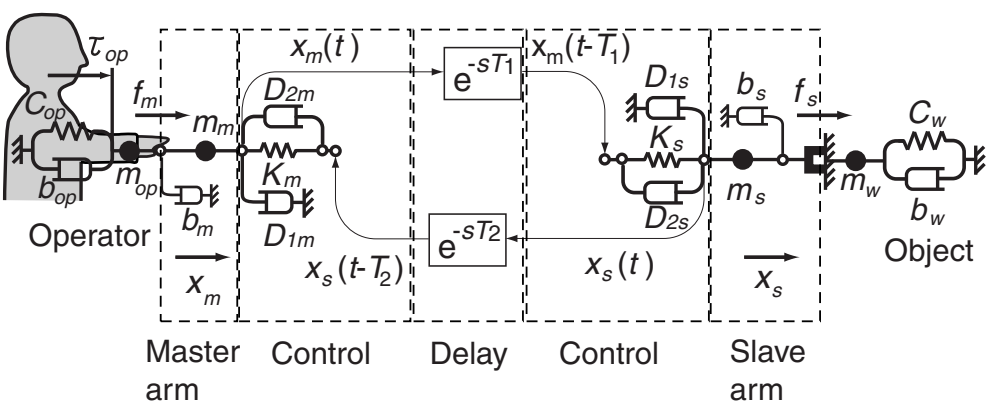

Figure 3: Master slave system with PD controller with grounded and relative damping gain.

$$
\begin{gathered}
D_{1 s}+b_{s} \geq 0 \\
\left(D_{1 m}+b_{m}\right)\left(D_{1 s}+b_{s}\right) \geq \frac{K_{m} K_{s}}{\omega^{2}} \sin ^{2} \frac{\omega\left(T_{1}+T_{2}\right)}{2} .
\end{gathered}
$$

Rewriting the right-hand side of (15), using the relationship $\sin \left(\omega\left(T_{1}+T_{2}\right) / 2\right)<\omega\left(T_{1}+T_{2}\right) / 2, \forall$ $\omega, T_{1}, T_{2}>0$, we get the following inequality:

$$
\left(D_{1 m}+b_{m}\right)\left(D_{1 s}+b_{s}\right) \geq \frac{K_{m} K_{s}\left(T_{1}+T_{2}\right)^{2}}{4} .
$$

If we consider a symmetrical system, i.e., $K_{m}=K_{s}=K, D_{1 m}=D_{1 s}=D_{1}, T_{1}=T_{2}=T, b_{m}=b_{s}=b$, then (15) and (16) become (17) and (18), respectively.

$$
\begin{gathered}
\left(D_{1}+b\right)^{2} \geq\left(\frac{K}{\omega} \sin \omega T\right)^{2} \\
D_{1}+b \geq K T
\end{gathered}
$$

\subsection{Stability of PD-based bilateral controller with grounded and relative damping}

We derive bilateral PD controller stability with grounded damping and relative damping. The physical interpretation of this controller is shown in Fig. 3.

As shown in Fig. 3, we added relative damping gains $D_{2 m}$ and $D_{2 s}$ in addition to grounded damping gains $D_{1 m}$ and $D_{1 s}$.

This type of $\mathrm{PD}$ controller is expressed by the following equations:

$$
\begin{aligned}
\tau_{m}= & -K_{m}\left(x_{m}(t)-x_{s}\left(t-T_{2}\right)\right) \\
& -D_{2 m}\left(\dot{x}_{m}(t)-\dot{x}_{s}\left(t-T_{2}\right)\right)-D_{1 m} \dot{x}_{m} \\
\tau_{s}= & K_{s}\left(x_{m}\left(t-T_{1}\right)-x_{s}(t)\right) \\
& +D_{2 s}\left(\dot{x}_{m}\left(t-T_{1}\right)-\dot{x}_{s}(t)\right)-D_{1 s} \dot{x}_{s} .
\end{aligned}
$$




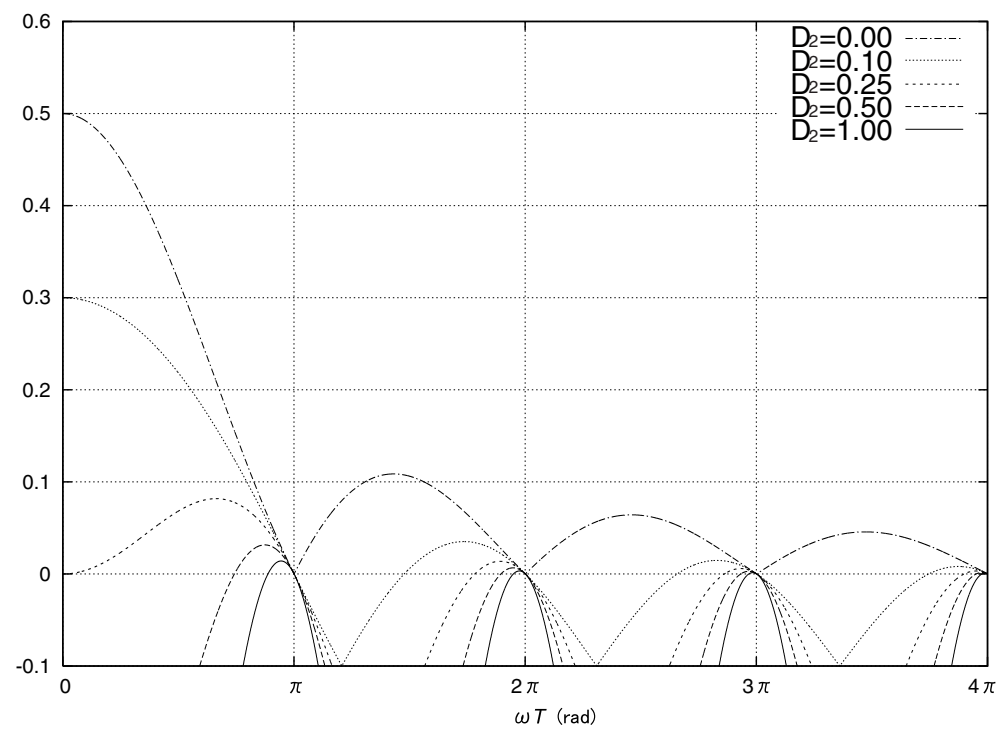

Figure 4: Numerical calculation results on the right side of eq. (24) ( $T=0.05 \mathrm{~s}, K=10.0 \mathrm{~N} / \mathrm{m})$.

The elements of the impedance matrix are

$$
\begin{aligned}
& z_{11}=m_{m} s+b_{m}+D_{1 m}+D_{2 m}+\frac{K_{m}}{s} \\
& z_{12}=\left(\frac{K_{m}}{s}+D_{2 m}\right) e^{-s T_{2}} \\
& z_{21}=\left(\frac{K_{s}}{s}+D_{2 s}\right) e^{-s T_{1}} \\
& z_{22}=m_{s} s+b_{s}+D_{1 s}+D_{2 s}+\frac{K_{s}}{s} .
\end{aligned}
$$

Again, for simplicity, we consider the above to be a symmetrical system, i.e. $K_{m}=K_{s}=K, D_{1 m}=$ $D_{1 s}=D_{1}, D_{2 m}=D_{2 s}=D_{2}$, and $T_{1}=T_{2}=T$.

Applying Llewellyn's criteria to (21), the teleoperator is stable for passive terminations if the following conditions are satisfied at all frequencies:

$$
\begin{gathered}
D_{1}+b+D_{2} \geq 0 \\
\left(D_{1}+b+D_{2}\right)^{2} \geq\left(D_{2} \cos \omega T-\frac{K}{\omega} \sin \omega T\right)^{2} .
\end{gathered}
$$

Eq. (23) can be rewritten as follows:

$$
D_{1}+b \geq\left|D_{2} \cos \omega T-\frac{K}{\omega} \sin \omega T\right|-D_{2} .
$$

By solving (24) numerically, we find parameters $D_{1}$ and $D_{2}$ satisfy (22) and (24) under given $K, T$, and $b$.

In Fig. 4, the numerical calculation results on the right side of (24) are shown. In this calculation, the parameters used are $T=0.05 \mathrm{~s}, K=10.0 \mathrm{~N} / \mathrm{m}$, and $D_{2}=0.00,0.10,0.25,0.50$ and $1.00 \mathrm{~N} \cdot \mathrm{s} / \mathrm{m}$. The case $D_{2}=0.00$ corresponds to a PD controller with only grounded damping, see Section 2.2. The 
Table 1: $\boldsymbol{H}$ and $\boldsymbol{G}$ matrix elements, physical interpretations and ideal values.

\begin{tabular}{|c|c|c|c|c|c|c|}
\hline \multirow{2}{*}{$\begin{array}{l}\text { Element } \\
\text { of } \\
\boldsymbol{H} \text { and } \boldsymbol{G} \\
\text { matrix }\end{array}$} & \multicolumn{5}{|c|}{ Physical interpretation } & \multirow{2}{*}{$\begin{array}{l}\text { Ideal } \\
\text { value }\end{array}$} \\
\hline & Condition & $\begin{array}{l}\text { Input } \\
\text { port }\end{array}$ & $\begin{array}{l}\text { Uutput } \\
\text { port }\end{array}$ & Interpretation & Conceptual figure & \\
\hline$h_{12}=\left.\frac{V_{m}}{V_{s}}\right|_{I_{m}=0}$ & \multirow{2}{*}{$\begin{array}{c}\text { Master } \\
\text { arm is } \\
\text { constrained }\end{array}$} & \multirow{4}{*}{ Master } & \multirow{4}{*}{ Slave } & Reverse force gain & 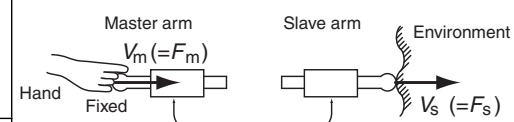 & 1 \\
\hline$h_{22}=\left.\frac{-I_{s}}{V_{s}}\right|_{I_{m}=0}$ & & & & 1/(Output impedance) & $I_{\mathrm{m}}\left(=\dot{x}_{m}\right)$ & 0 \\
\hline$h_{11}=\left.\frac{V_{m}}{I_{m}}\right|_{V_{s}=0}$ & \multirow{2}{*}{$\begin{array}{l}\text { Slave } \\
\text { arm is } \\
\text { free }\end{array}$} & & & Input impedance & Hand & 0 \\
\hline$h_{21}=\left.\frac{-I_{s}}{I_{m}}\right|_{V_{s}=0}$ & & & & Velocity gain & $I_{\mathrm{m}}\left(\dot{\left.=\dot{x}_{\mathrm{m}}\right)} \stackrel{\text { Signal transmission }}{I_{\mathrm{s}}\left(\dot{=} \dot{x}_{\mathrm{s}}\right)}\right.$ & -1 \\
\hline$g_{12}=\left.\frac{I_{m}}{-I_{s}}\right|_{V_{m}=0}$ & \multirow{2}{*}{$\begin{array}{l}\text { Master } \\
\text { arm is } \\
\text { free }\end{array}$} & \multirow{4}{*}{ Slave } & \multirow{4}{*}{ Master } & Velocity gain & Master arm Slave arm Environment & -1 \\
\hline$g_{22}=\left.\frac{V_{s}}{-I_{s}}\right|_{V_{m}=0}$ & & & & Input impedance & 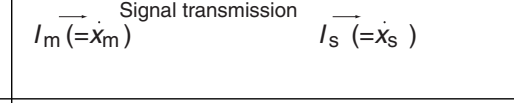 & 0 \\
\hline$g_{11}=\left.\frac{I_{m}}{V_{m}}\right|_{I_{s}=0}$ & \multirow{2}{*}{$\begin{array}{c}\text { Slave } \\
\text { arm is } \\
\text { constrained }\end{array}$} & & & 1/(Output impedance) & 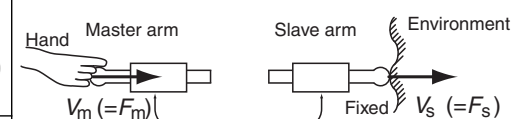 & 0 \\
\hline$g_{21}=\left.\frac{V_{s}}{V_{m}}\right|_{I_{s}=0}$ & & & & Reverse force gain & $I_{\mathrm{m}}\left(=\dot{x}_{\mathrm{m}}\right) \quad I_{\mathrm{s}}\left(\dot{=} \dot{x}_{\mathrm{s}}\right)$ & 1 \\
\hline
\end{tabular}

calculation shows that the grounded damping gain $D_{1}$ can be set smaller as a relative damping gain $D_{2}$ increases from zero. It should be noted that, in order to satisfy inequality (24) with $K>0, D_{1}+b$ cannot be zero no matter how large we set $D_{2}$.

\subsection{Teleoperator transparency as a performance measurement and evalua- tion using hybrid matrix and inverse hybrid matrix}

In this section, we study the performance measurement of bilateral teleoperators with two PD controllers, as shown in the previous section.

For bilataral teleoperation, a completely transparent teleoperation system is ideal, i.e., the operators feel that they are directly interacting with the remote task [7]. If this ideal is achieved, $V_{m}=V_{s}$ and $I_{s}=I_{m}$ are satisfied.

To measure the performance of the teleoperator quantitatively, Lawrence [7] calculated $z_{t} / z_{e}$ and compared it to the ideal value $1+0 j$, where $z_{t}$ is the impedance felt by the operator $\left(=V_{m} / I_{m}\right)$ and $z_{e}$ is the task impedance $\left(=V_{s} / I_{s}\right)$. Using this method, we evaluated how operator feeling is similar to the remote task, expressed as $z_{e}$. 
At first, we used the above quantitative method to measure the performance of a teleoperator by PD controller. When the task dynamics and the master arm dynamics are the same, $z_{e}$ approaches $z_{t}$ as the frequency increases. Therefore, the ratio $z_{t} / z_{e}$ approaches the ideal value $1+0 j$, even though the slave arm does not follow the master arm because of the high frequency motion of the master arm and the delay between the master and the slave. In this situation, even if the index $z_{t} / z_{e}$ is apparently equal to $1+0 j$, the slave arm actually cannot follow the master arm. So the situation is not ideal. The affect of delay between master and slave is not reflected by the index $z_{t} / z_{e}$. The interaction and tracking of the master and slave sides are not reflected by the index $z_{t} / z_{e}$.

According to the discussion above, the performance of our teleoperator with time delay cannot adequately be evaluated by this method. Therefore, we have come to the following conclusions.

Teleoperator performance is basically limited by master arm dynamics and slave arm dynamics. This is remarkable, especially in a high-frequency region. Next, we must discern how transmission characteristics from master to slave and from slave to master effect performance. Therefore, by evaluating each of these four characteristics, performance can be precisely measured. This can be executed by performance evaluation with the hybrid matrix $\boldsymbol{H}$, as proposed by Hannaford [4].

In the next section, we introduce the hybrid matrix expression of the teleoperator [4]. The four elements of the hybrid matrix are input impedance, reverse force gain, velocity gain, and 1/output impedance. These elements are derived from the master arm dynamics, the transmission characteristics from master to slave, the transmission characteristics from slave to master, and the slave arm dynamics.

\subsubsection{Performance measurement using $H$ matrix}

The teleoperator can be expressed by a hybrid matrix

$$
\left[\begin{array}{c}
V_{m} \\
-I_{s}
\end{array}\right]=\left[\begin{array}{ll}
h_{11} & h_{12} \\
h_{21} & h_{22}
\end{array}\right]\left[\begin{array}{l}
I_{m} \\
V_{s}
\end{array}\right]
$$

where $\boldsymbol{H}=\left[h_{i j}\right]$ is the hybrid matrix of the teleoperator. The physical interpretation of $h_{i j}$ is shown in Table 1.

If complete teleoperator transparency is achieved, the hybrid matrix becomes as follows:

$$
\boldsymbol{H}_{\text {ideal }}=\left[\begin{array}{ll}
0 & 1 \\
-1 & 0
\end{array}\right] \text {. }
$$

Therefore, teleoperator performance can be evaluated by how close the elements of the hybrid matrix are to the ideal values of $\boldsymbol{H}_{\text {ideal }}$.

From (21), the elements of the hybrid matrix of the teleoperator, see Section 2.3, are calculated as 
follows:

$$
\begin{aligned}
h_{11}= & M_{m} s+D_{2 m}+D_{1 m}+b_{m}+\frac{K_{m}}{s} \\
& -\frac{\left(D_{2 s}+\frac{K_{s}}{s}\right)\left(D_{2 m}+\frac{K_{m}}{s}\right) e^{-s\left(T_{1}+T_{2}\right)}}{M_{s} s+D_{1 s}+b_{s}+D_{2 s}+\frac{K_{s}}{s}} \\
h_{12}= & \frac{\left(D_{2 m}+\frac{K_{m}}{s}\right) e^{-s T_{2}}}{M_{s} s+D_{1 s}+b_{s}+D_{2 s}+\frac{K_{s}}{s}} \\
h_{21}= & -\frac{\left(D_{2 s}+\frac{K_{s}}{s}\right) e^{-s T_{1}}}{M_{s} s+D_{1 s}+b_{s}+D_{2 s}+\frac{K_{s}}{s}} \\
h_{22}= & \frac{1}{M_{s} s+D_{1 s}+b_{s}+D_{2 s}+\frac{K_{s}}{s}} .
\end{aligned}
$$

The values of $h_{11}, \cdots, h_{22}$ depend upon the frequency $\omega$. We calculate the limit of $h_{11}, \cdots, h_{22}$ as $\omega \rightarrow 0$ and $\omega \rightarrow \infty$ limit as shown in Table 2. In the far right column, the ideal values are shown. In case of the teleoperation with a time delay, the manipulation speed becomes slower because of the delay, therefore $h_{i j}(\omega \rightarrow 0)$ values are important. From the $h_{i j}(\omega \rightarrow 0)$ value in Table $2, K_{m}$ should be set equal to $K_{s}$ in order to achieve $\left|h_{12}\right| \rightarrow 1$ at $\omega \rightarrow 0$. Larger values of $K_{m}\left(=K_{s}\right)$ yields smaller $\left|h_{22}\right|$ and larger $\left|h_{11}\right|$. This relationship is a tradeoff. Longer delays cause a larger damping gain $D_{1}$, a larger $\left|h_{11}\right|$ and result in performance degradation. This means that the master arm responds in a resistant manner, even when the slave arm is free.

\subsubsection{Performance measurement using $G$ matrix}

Using $\boldsymbol{H}$ matrix, the performance can be evaluated more precisely than the simple index of $z_{t} / z_{e}$. However, as shown in Table 1, we can evaluate the performance with $\boldsymbol{H}$ matrix if the master arm is constrained or the slave arm is free. Here, we study the performance evaluation of other conditions.

In another expression, the teleoperator can be expressed using the $\boldsymbol{G}$ matrix:

$$
\left[\begin{array}{l}
I_{m} \\
V_{s}
\end{array}\right]=\left[\begin{array}{ll}
g_{11} & g_{12} \\
g_{21} & g_{22}
\end{array}\right]\left[\begin{array}{c}
V_{m} \\
-I_{s}
\end{array}\right]
$$

where $\boldsymbol{G}=\left[g_{i j}\right]$ is the inverse hybrid matrix of the teleoperator.

Using $\boldsymbol{G}$ matrix, we can evaluate the performance when the master arm is free and the slave arm is constrained, see Table 1.

If the complete transparency of the teleoperator is achieved, the inverse hybrid matrix becomes as follows:

$$
\boldsymbol{G}_{\text {ideal }}=\left[\begin{array}{ll}
0 & -1 \\
1 & 0
\end{array}\right] .
$$

The limits of $g_{11}, \cdots, g_{22}$ as $\omega \rightarrow 0$ and $\omega \rightarrow \infty$ are shown in Table 2 .

The relationship between $\boldsymbol{G}$ matrix and $\boldsymbol{H}$ matrix is

$$
\boldsymbol{G}=\boldsymbol{H}^{-1}=\left[\begin{array}{cc}
\frac{h_{22}}{\Delta H} & -\frac{h_{12}}{\Delta H} \\
-\frac{h_{21}}{\Delta H} & \frac{h_{11}}{\Delta H}
\end{array}\right]
$$


Table 2: Limit value of hybrid matrix elements and ideal value achieved by perfect transparency.

\begin{tabular}{|c|c|c|c|c|c|c|}
\hline \multirow{2}{*}{ Matrix } & \multirow{2}{*}{ Elements } & \multicolumn{2}{|l|}{$\omega \rightarrow 0$} & \multicolumn{2}{|l|}{$\omega \rightarrow \infty$} & \multirow{2}{*}{$\begin{array}{l}\text { Ideal } \\
\text { value }\end{array}$} \\
\hline & & Gain & Phase & Gain & Phase & \\
\hline \multirow{6}{*}{$\boldsymbol{H}$} & $h_{11}$ & $D_{1 m}+\frac{K_{m}\left(D_{1 s}+b_{s}\right)}{K_{s}}+K_{m}\left(T_{1}+T_{2}\right)$ & 0 & $M_{m} \omega$ & $\frac{\pi}{2}$ & 0 \\
\hline & \multirow{2}{*}{$h_{12}$} & \multirow{2}{*}{$\frac{K_{m}}{K_{s}}$} & \multirow{2}{*}{0} & $K_{m} / M_{s} \omega^{2}\left(\right.$ if $\left.D_{2 m}=0\right)$ & \multirow{2}{*}{$-\infty$} & \multirow{2}{*}{1} \\
\hline & & & & $D_{2 m} / M_{s} \omega\left(\right.$ if $\left.D_{2 m} \neq 0\right)$ & & \\
\hline & \multirow{2}{*}{$h_{21}$} & \multirow{2}{*}{1} & \multirow{2}{*}{$\pi$} & $K_{s} / M_{s} \omega^{2}\left(\right.$ if $\left.D_{2 s}=0\right)$ & \multirow{2}{*}{$-\infty$} & \multirow{2}{*}{-1} \\
\hline & & & & $D_{2 s} / M_{s} \omega\left(\right.$ if $\left.D_{2 s} \neq 0\right)$ & & \\
\hline & $h_{22}$ & $\frac{\omega}{K_{s}}$ & $\frac{\pi}{2}$ & $\frac{1}{M_{s} \omega}$ & $-\frac{\pi}{2}$ & 0 \\
\hline \multirow{6}{*}{$G$} & $g_{11}$ & $\frac{\omega}{K_{m}}$ & $\frac{\pi}{2}$ & $\frac{1}{M_{m} \omega}$ & $-\frac{\pi}{2}$ & 0 \\
\hline & \multirow{2}{*}{$g_{12}$} & \multirow{2}{*}{1} & \multirow{2}{*}{$\pi$} & $K_{m} / M_{m} \omega^{2}\left(\right.$ if $\left.D_{2 m}=0\right)$ & \multirow{2}{*}{$-\infty$} & \multirow{2}{*}{-1} \\
\hline & & & & $D_{2 m} / M_{m} \omega\left(\right.$ if $\left.D_{2 m} \neq 0\right)$ & & \\
\hline & \multirow{2}{*}{$g_{21}$} & \multirow{2}{*}{$\frac{K_{s}}{K_{m}}$} & \multirow{2}{*}{0} & $K_{s} / M_{m} \omega^{2}\left(\right.$ if $\left.D_{2 s}=0\right)$ & \multirow{2}{*}{$-\infty$} & \multirow{2}{*}{1} \\
\hline & & & & $D_{2 s} / M_{m} \omega\left(\right.$ if $\left.D_{2 s} \neq 0\right)$ & & \\
\hline & $g_{22}$ & $D_{1 s}+\frac{K_{s}\left(D_{1 m}+b_{m}\right)}{K_{m}}+K_{s}\left(T_{1}+T_{2}\right)$ & 0 & $M_{s} \omega$ & $\frac{\pi}{2}$ & 0 \\
\hline
\end{tabular}

where

$$
\Delta H=h_{11} h_{22}-h_{12} h_{21} .
$$

Using the elements of the impedance matrix, $\Delta H$ is rewritten as

$$
\Delta H=\frac{z_{11}}{z_{22}} .
$$

When $z_{11}=z_{22}$, we obtain the following equation

$$
\left[\begin{array}{ll}
g_{11} & g_{12} \\
g_{21} & g_{22}
\end{array}\right]=\left[\begin{array}{cc}
h_{22} & -h_{12} \\
-h_{21} & h_{11}
\end{array}\right] .
$$

Therefore, if the arm dynamics and the controller designs are the same as the master and the slave, and $z_{11}=z_{22}$ is true, the performance of the teleoperator under the four conditions shown in Table 1 can be evaluated by computing either the $\boldsymbol{H}$ or $\boldsymbol{G}$ matrix. In this situation, if $\boldsymbol{H}$ is equal to the ideal values of $\boldsymbol{H}$, the ideal response is realized. However, it is impossible to realize the ideal value with all 4 elements of $\boldsymbol{H}$. For example, if we select high position gain to improve the performance of the slave constraint condition, the performance of the slave free condition degrades. Therefore, the designer must choose important factors and design gains in consideration of the task characteristics.

On the other hand, if the parameters or gain settings between master and slave are different, the 


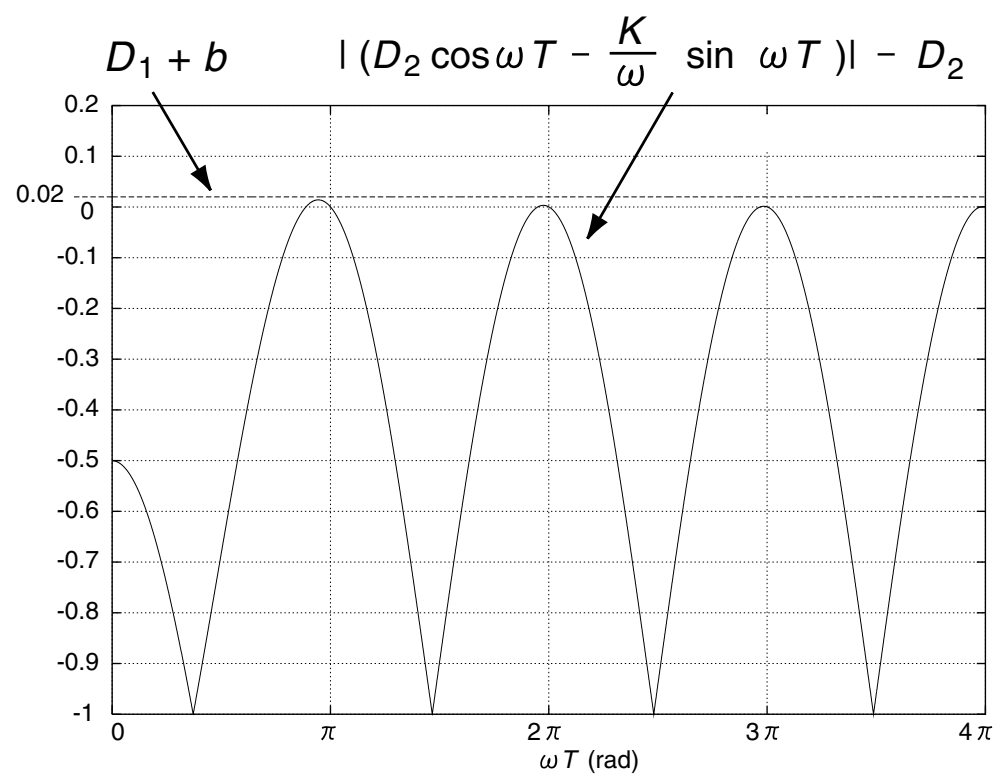

Figure 5: Plot of the stability condition and $D_{1}$ gain setting. The solid line is the right side of (24) and the dashed line is the left side of (24).

evaluation of $\boldsymbol{G}$ includes information different from the evaluation of $\boldsymbol{H}$. Therefore, both $\boldsymbol{H}$ and $\boldsymbol{G}$ have to be considered to evaluate the performance. In the case of a scaled teleoperator with force or position scaling, the ideal values of $\boldsymbol{H}$ and $\boldsymbol{G}$ are not the values shown in Table 2. They are the values determined by its scaling factor. The performance measurement of a scaled teleoperator with a hybrid matrix is discussed in appendix A.

\section{1-DOF SIMULATION AND CONTROLLER DESIGN}

\subsection{Controlled system and controller design}

In this section we show the results of 1-DOF numerical simulations. We assume a linear master slave system as shown in Figs. 1 and 3. To confirm the effect of relative damping, we compare the two controller types. In the simulations, we assume the time delay $T_{1}=T_{2}=T=0.05 \mathrm{~s}$, the arm inertia $M_{m}=M_{s}=M=1 \mathrm{~kg}$, and the mechanism viscous coefficient $b_{m}=b_{s}=b=0 \mathrm{~N} \cdot \mathrm{s} / \mathrm{m}$.

We designed two controllers. Type A controller is a PD controller with grounded damping, as shown in Section 2.2. Type B controller is a PD controller with grounded and relative damping, as shown in Section 2.3. With both types, we set the controller proportional gain, $K_{m}=K_{s}=K=10 \mathrm{~N} / \mathrm{m}$. With type A, we set $D_{2}$ to satisfy condition (18). With type B controller, we set $D_{2}$ gain, $D_{2 m}=D_{2 s}=D_{2}=$ $1.0 \mathrm{~N} \cdot \mathrm{s} / \mathrm{m}$. Using numerical calculation, we set $D_{1 m}=D_{1 s}=D_{1}=0.02 \mathrm{~N} \cdot \mathrm{s} / \mathrm{m}$ to satisfy the stability condition (24). Fig. 5 shows the result of numerical calculation with $D_{1}$ gain setting.

Table 3 shows the controller gains. Fig. 6 shows the bode plot of each element of the hybrid matrix 
Table 3: Gain settings for both controllers: Type A and Type B.

\begin{tabular}{|l||l|l|l|l|}
\hline Type & $K[\mathrm{~N} / \mathrm{m}]$ & $D_{1}[\mathrm{~N} \cdot \mathrm{s} / \mathrm{m}]$ & $D_{2}[\mathrm{~N} \cdot \mathrm{s} / \mathrm{m}]$ & Description \\
\hline A & 10.0 & 0.5 & 0.0 & PD controller with grounded damping \\
\hline B & 10.0 & 0.02 & 1.0 & $\begin{array}{l}\text { PD controller with grounded damping } \\
\text { and relative damping }\end{array}$ \\
\hline
\end{tabular}

Table 4: Simulation parameter settings.

\begin{tabular}{|l||l|l|l|l|l|}
\hline Case No. & $\begin{array}{l}\text { Controller } \\
\text { type }\end{array}$ & $\begin{array}{l}\text { Slave side } \\
\text { environment }\end{array}$ & $\begin{array}{l}C_{w} \\
{[\mathrm{~N} / \mathrm{m}]}\end{array}$ & $\begin{array}{l}M_{w} \\
{[\mathrm{~kg}]}\end{array}$ & $\begin{array}{l}b_{w} \\
{[\mathrm{~N} \cdot \mathrm{s} / \mathrm{m}]}\end{array}$ \\
\hline 1 & A & Mass hold & 0.0 & 1.0 & 0.0 \\
\hline 2 & B & Mass hold & 0.0 & 1.0 & 0.0 \\
\hline 3 & A & Constrained by elastic wall & 100.0 & 0.0 & 0.0 \\
\hline 4 & B & Constrained by elastic wall & 100.0 & 0.0 & 0.0 \\
\hline
\end{tabular}

for both types of controller. In the low-frequency area, $\left|h_{11}\right|$ is closer to the ideal value for a type $\mathrm{B}$ controller. The magnitude of $h_{11}$ at $\omega \rightarrow 0$ is 2.0 with a type A controller, while it is 1.04 with a type B controller. The ideal value is $\left|h_{11}\right|=0.0$. This means that a type $\mathrm{B}$ controller is less conservative than a type A controller in the low frequency region, including direct current. By adding the relative damping gain, the grounded damping gain can be attenuated and overall conservativeness is reduced. Around $\omega=3 \mathrm{rad} / \mathrm{s},\left|h_{22}\right|$ is closer to the ideal value in the a type B controller than the a type A. In the high frequency region, $h_{11}$ and $h_{22}$ approach $M_{m} \omega$ and $1 / M_{s} \omega$, respectively, $M_{m} \omega$ and $1 / M_{s} \omega$ represent the dynamics of master and slave.

\subsection{Simulation cases}

Using the control law designed in the previous section, we conducted simulations. The tasks were a mass pushing task and a wall pushing task. Table 4 shows the simulation cases and parameter settings. To compare the controller performance using two environmental settings, we calculated four simulation cases. In all cases, the initial state is $x_{m}=0, x_{s}=0, \dot{x}_{m}=0$, and $\dot{x}_{s}=0$.

In all cases, we assume that the operator applies a force of $1 \mathrm{~N}$ for $10 \mathrm{~s}$ to the master arm from $t=10 \mathrm{~s}$ to $t=20 \mathrm{~s}$, see Figs. 7 and 8.

We set the slave environment as in Table 4 . In cases 1 and 2, the slave environment is a simple mass hold. In case 3 and 4 , the slave arm is constrained by an elastic wall. The natural position of the elastic wall is $x_{s}=0$. 

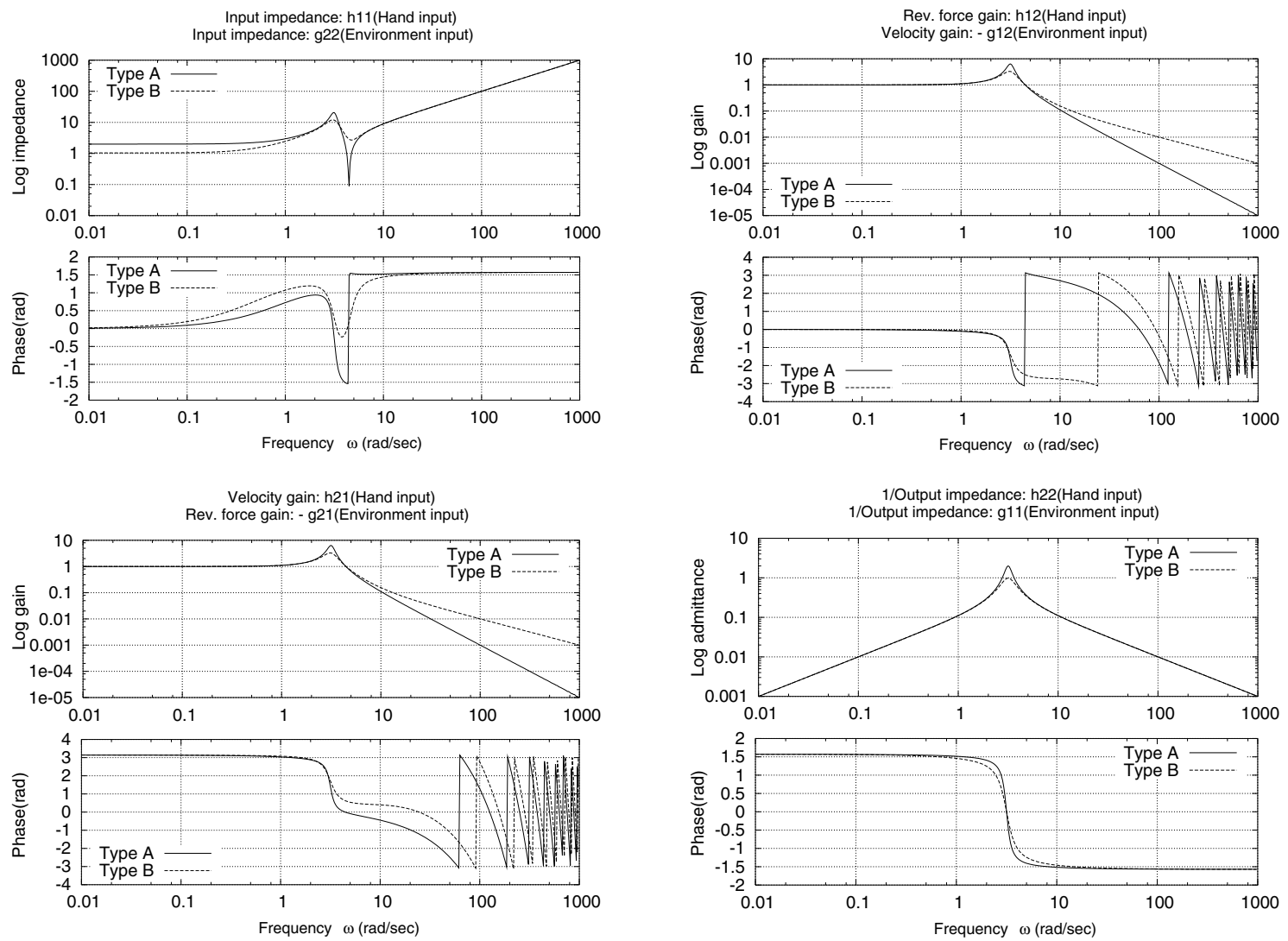

Figure 6: Frequency-dependent $H$ and $G$ matrix of a Type A controller (only grounded damping) and a Type B controller (with grounded and relative damping).

\subsection{Simulation result and discussion}

Figs. 7 and 8 show the simulation results of the mass pushing task and the wall pushing task. In Fig. 8, the ideal response is the master arm position and the slave position are the same, and the force at the master arm and the force at slave arm are the same. In the mass pushing task, the mass moves slower than the ideal response because of the viscous force of the damping gain and the inertia of the arms. However, the mass moves more quickly with the type B controller than the type A. This result agrees with the low-frequency $h_{11}$ value in Fig. 6. The fluctuation of force at the slave arm is less with a type B controller, see Fig.7(b). In the wall pushing task, the fluctuation of the arm position is observed. Fluctuation of arm positions occurs around the frequency of $0.5 \mathrm{~Hz}$ and is smaller with a type B controller. This result agrees with the $g_{11}$ value in Fig. 6. The simulation results and performance evaluation results of $\boldsymbol{H}$ are consistent. Appendix B shows the simulation results on the slave side of the rigid wall environment. 


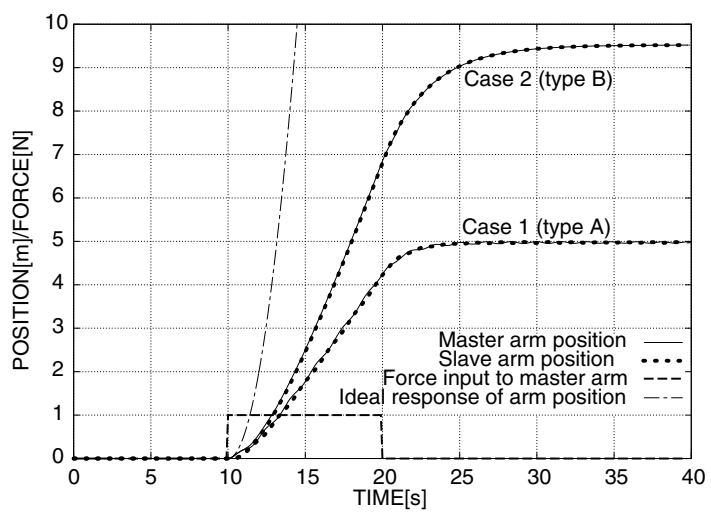

(a)

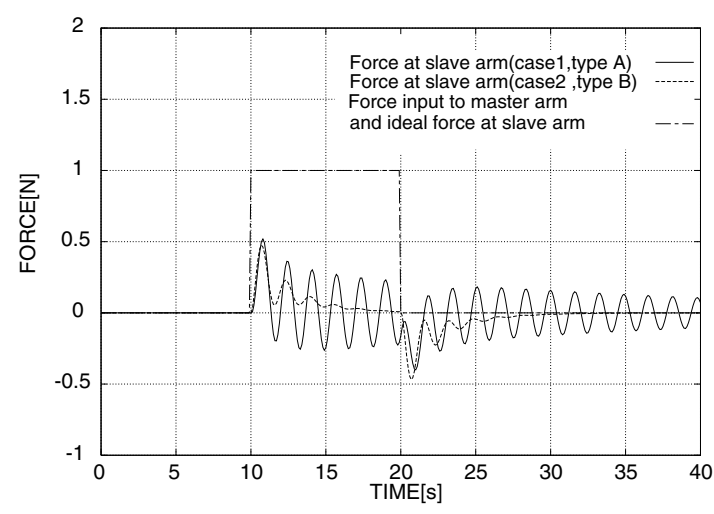

(b)

Figure 7: Simulation results. The slave environment is mass hold. Operator force of $1 \mathrm{~N}$ is inputted to the master arm for $10 \mathrm{~s}$. Case 1 is PD with grounded damping and Case 2 is PD with grounded and relative damping.

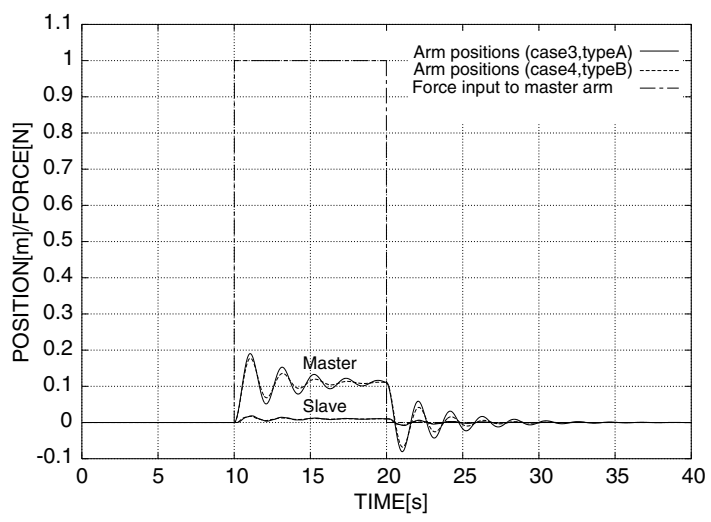

(a)

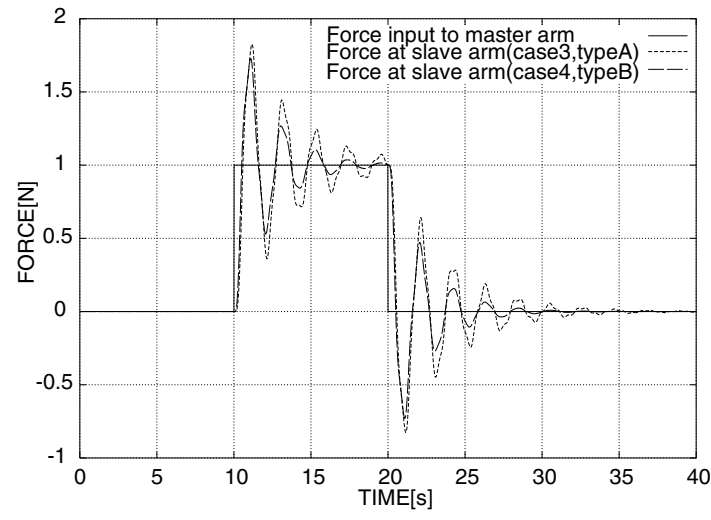

(b)

Figure 8: Simulation results. The slave environment is an elastic wall. Operator force of $1 \mathrm{~N}$ is inputted to the master arm for $10 \mathrm{~s}$. Case 3 is PD with grounded damping and Case 4 is PD with grounded and relative damping. 


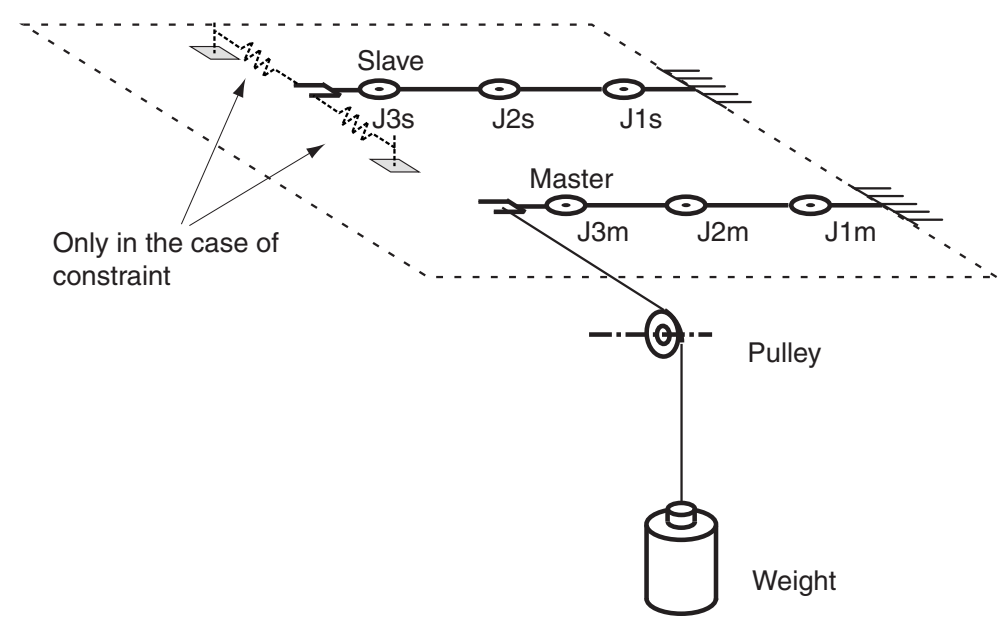

Figure 9: 1-DOF experimental setup.

\section{1-DOF EXPERIMENT}

To confirm the effectiveness of the proposed controller and the validity of the simulation results, we conducted an experiment with a pair of manipulators.

\subsection{Experimental System and Experimental Cases}

Fig. 9 shows the experimental master-slave system. The master and slave arms are 3-DOF planar-type manipulators with electric motors, harmonic-drive reduction gears, and an encoder at each joint. In this experiment, the elbow and wrist joints $(\mathrm{J} 2 \mathrm{~m}, \mathrm{~J} 2 \mathrm{~s}, \mathrm{~J} 3 \mathrm{~m}, \mathrm{~J} 3 \mathrm{~s})$ are fixed, and only 1 DOF is used. The arm length is $0.7 \mathrm{~m}$. A torque sensor is attached to each joint and each joint is controlled by a Torque Servo Actuator (TSA) [11]. The measured torque error is fed back to the servo controller and a fine torque control of the output axis is achieved. Using TSA control, undesirable friction torque generated by the harmonic-drive gear is compensated and attenuated. TSA gain at the shoulder joint is 12. A PC with an Athlon microprocessor $(1.9 \mathrm{GHz})$ is used to control both arms. The sampling period is $1.0 \mathrm{~ms}$, and the control law calculation frequency is $1 \mathrm{kHz}$. Each time delay from master to slave and from slave to master is $50 \mathrm{~ms}$. The time delay is calculated with software. The signals are buffered in the memory for the time delay. Inertial parameters of the master and the slave arms are $M_{m}=M_{s}=1.27 \mathrm{~kg} \cdot \mathrm{m}^{2}$. Table 5 shows the experimental cases and gain settings. The cases and gain settings are similar to those shown in Section 3.2. In the case of an elastic wall environment, the slave arm tip is connected to an elastic cord, and the elastic constant is $48 \mathrm{~N} \cdot \mathrm{m} / \mathrm{rad}$ at the shoulder joint. In order to apply a constant force to the master, we used a pulley and a weight, see Fig. 9.

\subsection{Experimental Results}

Fig. 10 shows the experimental results. We conducted the same experiment three times. Fig. 11 shows the typical time response of a 1-DOF experiment. Fig. 12 shows the motor command. In Fig. 11, we 
Table 5: 1-DOF experiment cases and gain settings.

\begin{tabular}{|c|c|c|c|c|c|c|c|c|}
\hline \multirow{2}{*}{$\begin{array}{l}\text { Case } \\
\text { No. }\end{array}$} & \multirow{2}{*}{$\begin{array}{c}K \\
{[\mathrm{~N}} \\
/ \mathrm{rad}]\end{array}$} & \multirow{2}{*}{$\begin{array}{c}D_{1} \\
{[\mathrm{~N} \cdot \mathrm{s}} \\
/ \mathrm{rad}]\end{array}$} & \multirow{2}{*}{$\begin{array}{c}D_{2} \\
{[\mathrm{~N} \cdot \mathrm{s}} \\
/ \mathrm{rad}]\end{array}$} & \multirow{2}{*}{$\begin{array}{c}\text { Slave side } \\
\text { environment }\end{array}$} & \multicolumn{2}{|c|}{ Force applied to the master arm } & \multirow[t]{2}{*}{ Result } & \multirow{2}{*}{$\begin{array}{c}\text { Typical } \\
\text { time } \\
\text { response }\end{array}$} \\
\hline & & & & & Tip force $[\mathrm{gf}]$ & $\begin{array}{c}\text { Equivalent joint } \\
\text { torque }[\mathrm{N} \cdot \mathrm{m}]\end{array}$ & & \\
\hline 1 & 10 & 0.5 & 0.0 & Free & 100 & 0.68 & \multirow{2}{*}{ Fig. 10(a) } & Fig. 11 (a) \\
\hline 2 & 10 & 0.02 & 1.0 & Free & 100 & 0.68 & & Fig. $11(b)$ \\
\hline 3 & 10 & 0.5 & 0.0 & Elastic wall & 200 & 1.36 & \multirow{2}{*}{ Fig. 10(b) } & Fig. $11(\mathrm{c})$ \\
\hline 4 & 10 & 0.02 & 1.0 & Elastic wall & 200 & 1.36 & & Fig. $11(d)$ \\
\hline
\end{tabular}

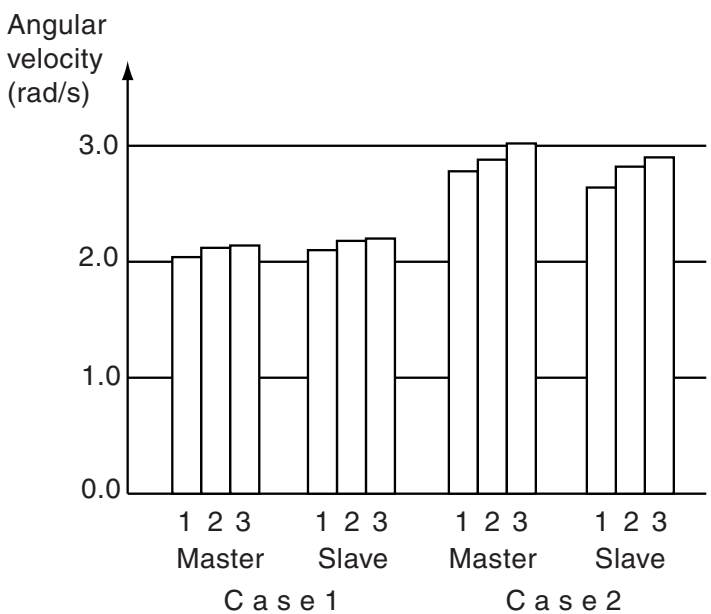

(a) Arm angular velocity in free motion

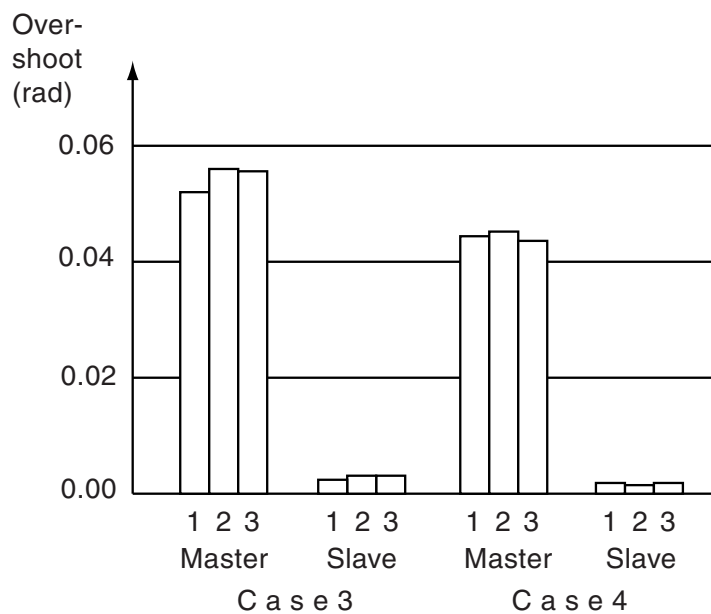

(b) Overshoot upon contacting the wall

Figure 10: 1-DOF experimental result.

plotted simulation results as well as experimental results. In the simulation, the joint friction of the real hardware $0.05 \mathrm{~N} \cdot \mathrm{m}$ is included. In the case of free motion, because of the viscous force of the damping gain, the arm movement is sticky. However, as shown in Figs. 10 and 11, the arm moves more quickly with a type B controller than a type A when the same force is applied to the master arm. In the case of an elastic wall environment, overshoot of the arm position at the moment of wall contact is observed. The overshoot is smaller with controller type B than type A. The simulation results and experimental results are consistent. In Fig.12, the motor command fluctuation in free motion is less with a type B controller.

\section{2-DOF PEG-IN-HOLE EXPERIMENT}

\subsection{Experimental system and experimental cases}

To confirm the effectiveness of the proposed control law in a realistic multi-DOF plant, we conducted a 2-DOF peg-in-hole task. The passivity of a 2-DOF system is discussed in Appendix C. Fig. 13 shows 


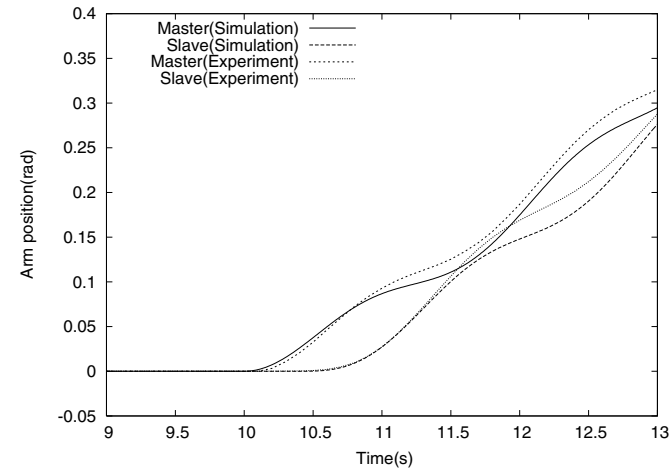

(a) Free motion with type A controller (Case 1)

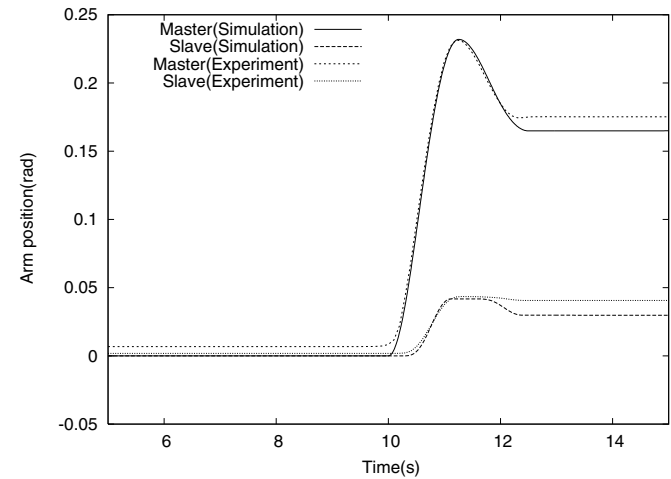

(c) Wall contact with type A controller (Case3)

Figure 11: Typical time response in 1-DOF experiments: Type A an Type B controllers.

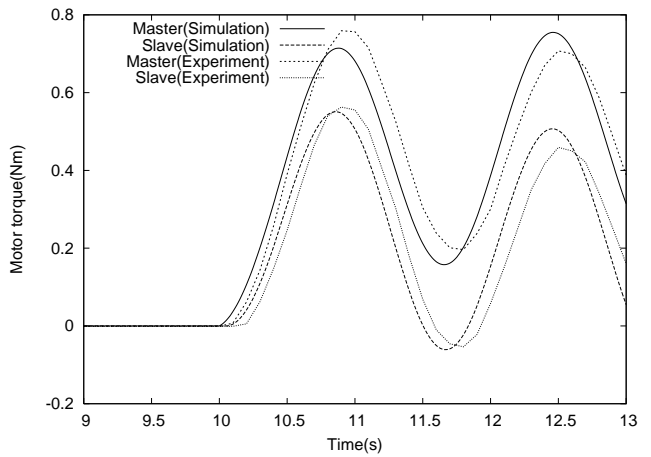

(a) Free motion with type A controller (Case 1)

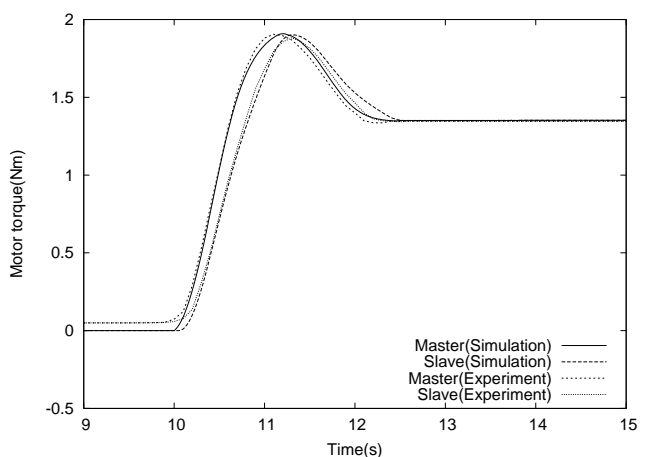

(c) Wall contact with type A controller (Case3)

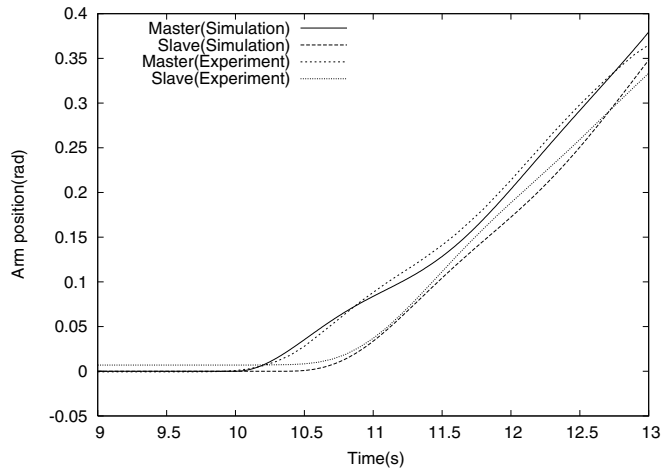

(b) Free motion with type B controller (Case 2)

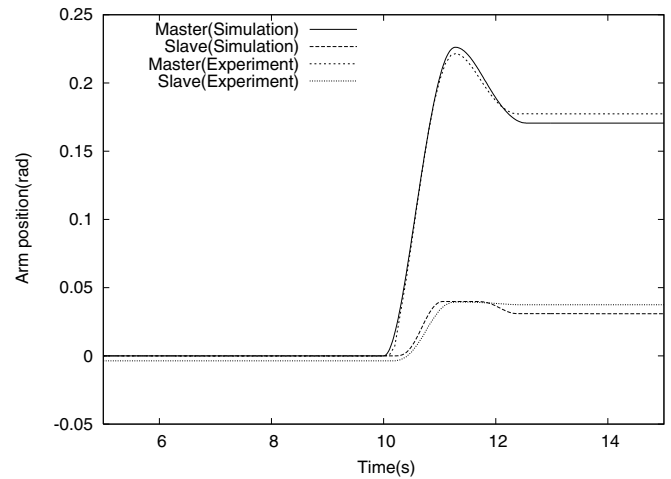

(d) Wall contact with type B controller (Case4)

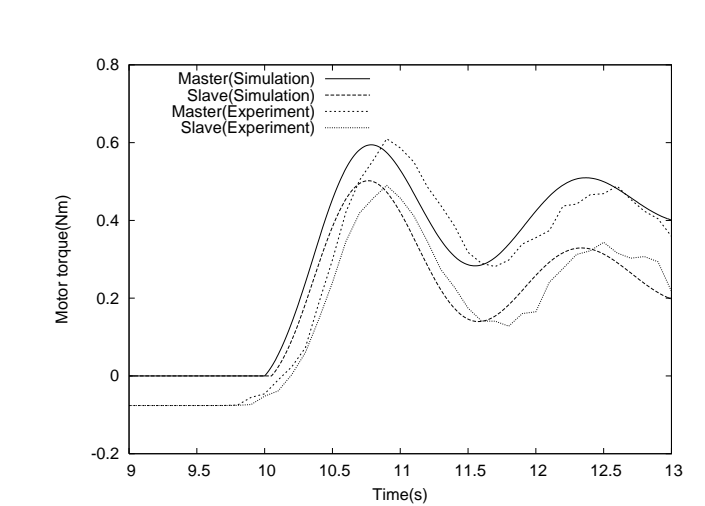

(b) Free motion with type B controller (Case 2)

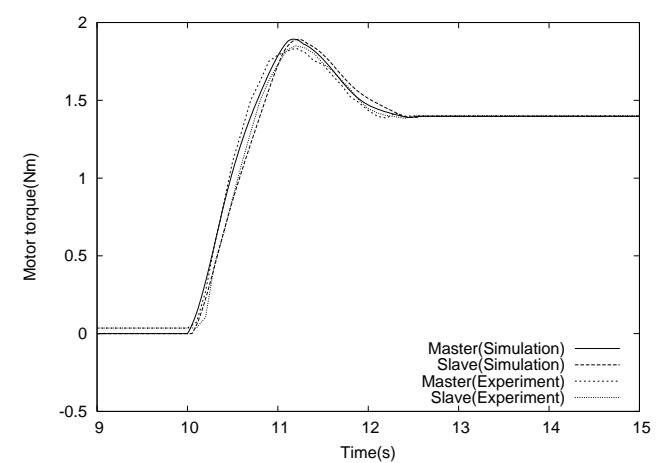

(d) Wall contact with type B controller (Case4)

Figure 12: Motor command of 1-DOF experiment. 
Table 6: 2-DOF peg-in-hole experiment test cases and results.

\begin{tabular}{|c|c|c|c|c|c|c|c|c|c|}
\hline $\begin{array}{l}\text { Case } \\
\text { No. }\end{array}$ & $\begin{array}{l}\text { Control } \\
\text { ler } \\
\text { type }\end{array}$ & $\begin{array}{l}K \\
{[\mathrm{~N} / \mathrm{rad}]}\end{array}$ & $\begin{array}{l}D_{1} \\
{[\mathrm{~N} \cdot} \\
\mathrm{s} / \mathrm{rad}]\end{array}$ & $\begin{array}{l}D_{2} \\
{[\mathrm{~N} .} \\
\mathrm{s} / \mathrm{rad}]\end{array}$ & $\begin{array}{l}\text { Visual } \\
\text { infor- } \\
\text { mation }\end{array}$ & $\begin{array}{l}\text { Task } \\
\text { completion } \\
\text { time }\end{array}$ & $\begin{array}{l}\text { Position } \\
\text { deviation }\end{array}$ & $\begin{array}{l}\text { Typical } \\
\text { arm tip } \\
\text { trajectory }\end{array}$ & $\begin{array}{l}\text { Motor } \\
\text { command } \\
\text { deviation }\end{array}$ \\
\hline 1 & A & 50.0 & 2.5 & 0.0 & Yes & \multirow{4}{*}{ Fig. 15(a) } & \multirow{4}{*}{ Fig. 15(b) } & Fig. 16 & \multirow{4}{*}{ Fig. 20} \\
\hline 2 & B & 50.0 & 0.1 & 5.0 & Yes & & & Fig. 17 & \\
\hline 3 & $\mathrm{~A}$ & 50.0 & 2.5 & 0.0 & No & & & Fig. 18 & \\
\hline 4 & B & 50.0 & 0.1 & 5.0 & No & & & Fig. 19 & \\
\hline
\end{tabular}

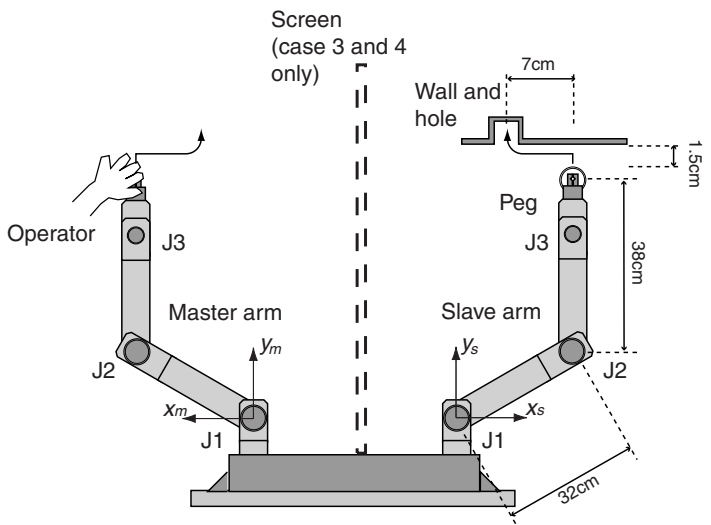

(a) Task and initial position

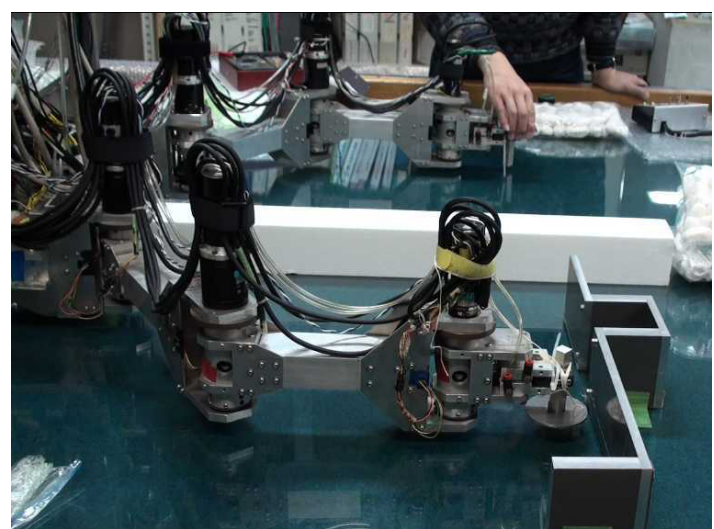

(b) Experiment

Figure 13: Setup of 2-DOF peg-in-hole experiment.

the experiment setup, the same hardware as in 4.1. As shown in Fig. 13, the master and the slave arms move symmetrically, therefore the direction of $x_{m}$ and $x_{s}$ are opposite. Table 6 shows the experiments and their gain settings. The controller gain of joint 1 and 2 are the same. Each time delay from master to slave and from slave to master is $50 \mathrm{~ms}$. The control law calculation frequency is $1 \mathrm{kHz}$. As a peg, an aluminum disk of $74 \mathrm{~mm}$ diameter is attached at the slave arm tip. The hole, an opening of $74 \mathrm{~mm}$ gap is in a wall, see Fig. 13. The desired task is to push the wall in $+\mathrm{y}$ direction, trace the wall toward $-\mathrm{x}$ direction, and insert the peg into the hole. The arm lengths are shown in Fig. 13. The parameters of the master and the slave are the same. The hole is located at the position of $x=-0.3 \mathrm{~m}$. In cases 1 and 2, the operator can see the slave side. In cases 3 and 4, a screen is located between master and slave. Therefore, the operator cannot see the slave, and the operator operates with only force information. The operator's view is shown in Fig. 14. 


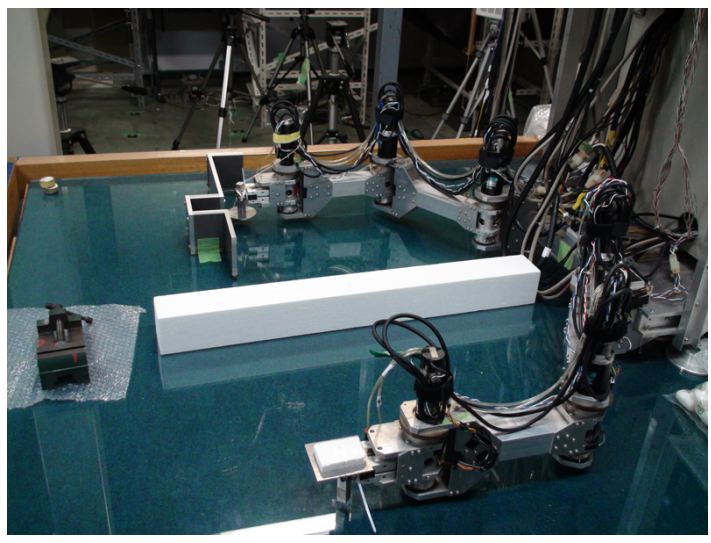

(a) Cases 1 and 2

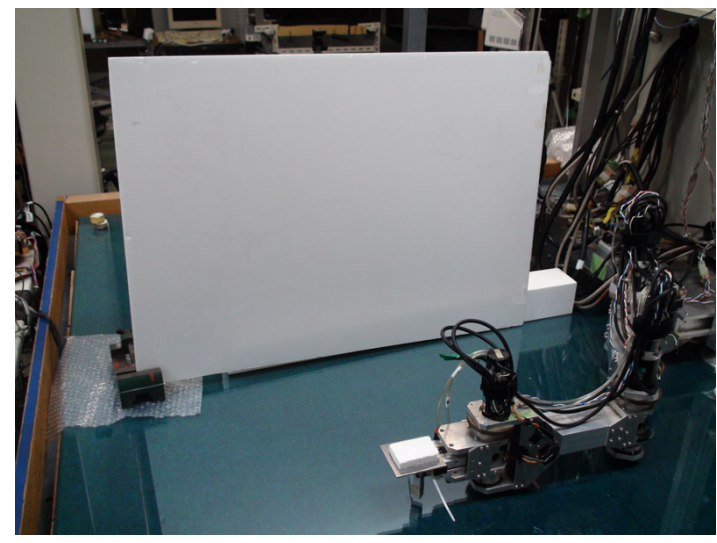

(b) Cases 3 and 4

Figure 14: Operator's view of slave side.

\subsection{Experimental result and discussion}

Fig. 15 shows experimental results. Figs. 16 to 19 show typical arm tip trajectory and motor command time plots. Along the lines illustrating the arm tip trajectories, the circles represent the arm tip positions at the time of adjacent numbers. The time is from the beginning of the experiment. As seen in Figs. 16 to 19 , tasks can be completed even without transmitting visual information to the operator. From this, we can tell that the force information to the operator is effective. In Fig. 15, task completion time is shown. When the peg insertion on the slave side reaches the bottom of the hole, we consider the task completed. In cases with visual information, the task completion times are shorter than in cases without visual information. As shown in Fig. 15, a type B controller completes the task more quickly than a type A.

As for position tracking, ideally, the trajectory of the master arm and the slave arm are the same. In Fig. 15, the average position tracking error of master tip and slave tip during the operation is shown. The position tracking performance is better with a type $\mathrm{B}$ controller than a type $\mathrm{A}$. The position difference in $\mathrm{x}$ direction during the peg insertion is smaller with a type $\mathrm{B}$ controller. Therefore, the operator can acknowledge the position of the hole more accurately with a type B controller.

A force sensor is not attached at the arm tip. Therefore we cannot measure the arm tip force and evaluate the force tracking. However, the transparency of the control law itself can be evaluated by the motor command error between master and slave. The result is shown in Fig.20. The error during the task is smaller with a type B controller than a type A controller. The transparency of control law is better with type B.

\section{CONCLUSION}

The stabilizing effect and performance improvement by introducing a relative damper to a PD-based teleoperator with time delay has been studied. First, we derived the stability condition of a PD-based controller with only grounded damping, and with both grounded and relative damping. By introducing 


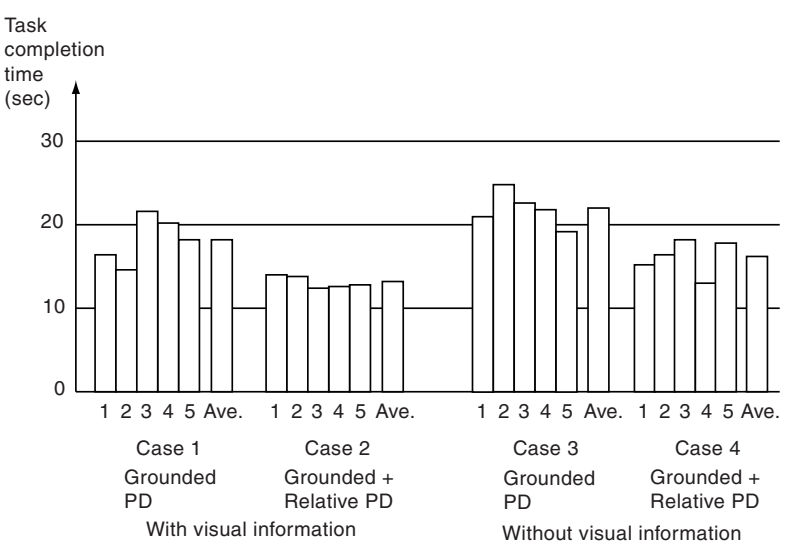

(a) Task completion time

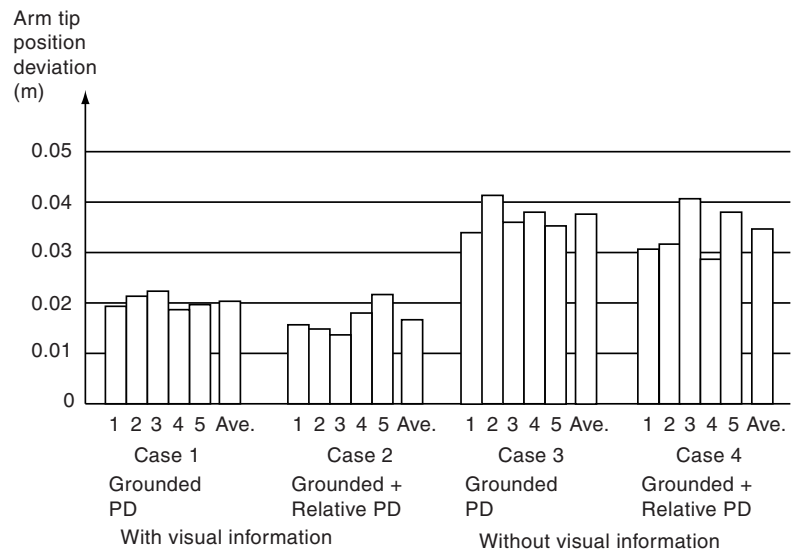

(b) Position deviation between master and slave arm

Figure 15: 2-DOF experimental results. Task completion time and arm tip position deviation: 5 time trials and their average value is shown.

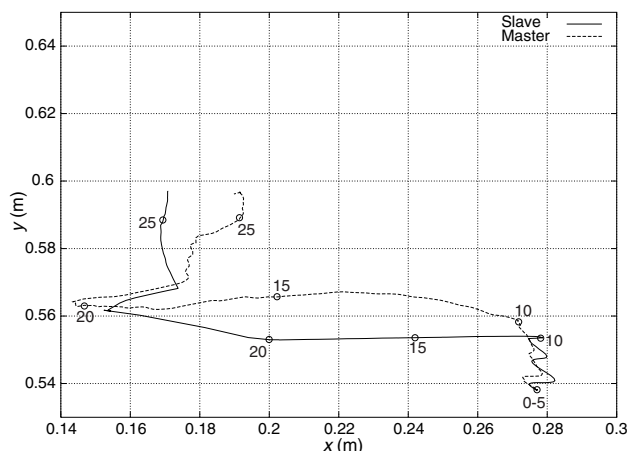

(a) Arm tip trajectory

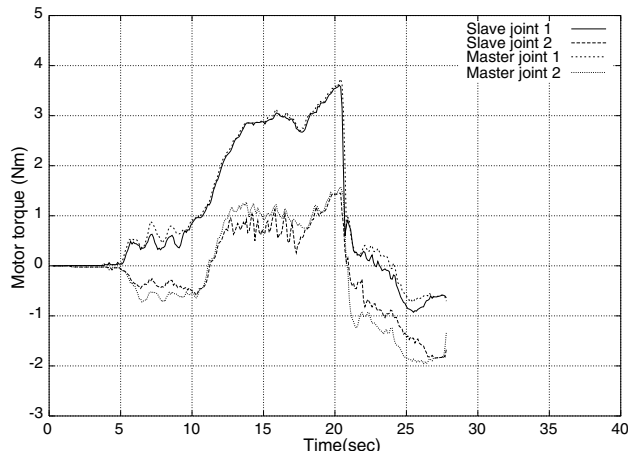

(b) Motor command

Figure 16: 2-DOF peg-in-hole experiment results with visual information (Type A controller).

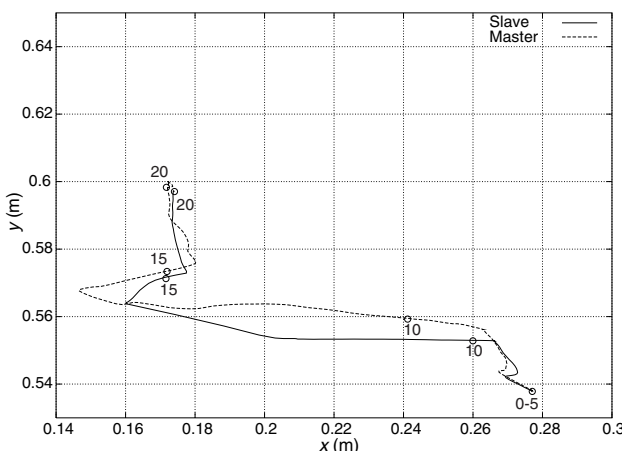

(a) Arm tip trajectory

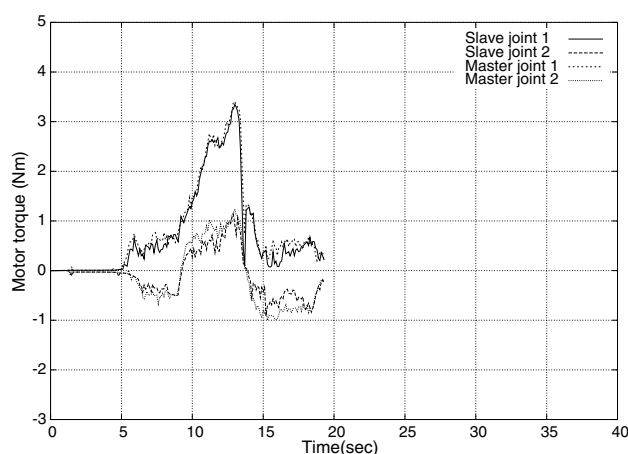

(b) Motor command

Figure 17: 2-DOF peg-in-hole experiment results with visual information (Type B controller). 


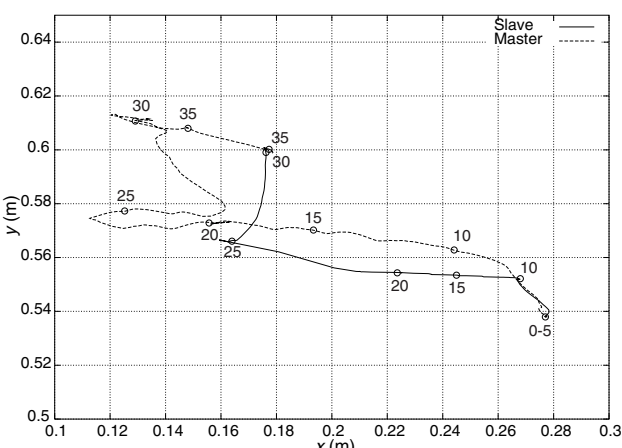

(a) Arm tip trajectory

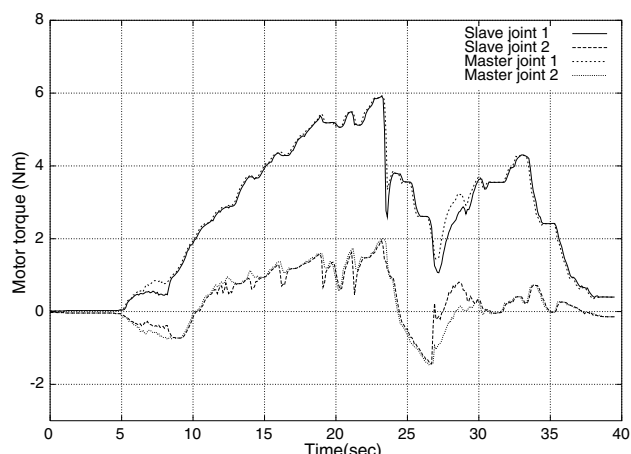

(b) Motor command

Figure 18: 2-DOF peg-in-hole experiment results without visual information (Type A controller).

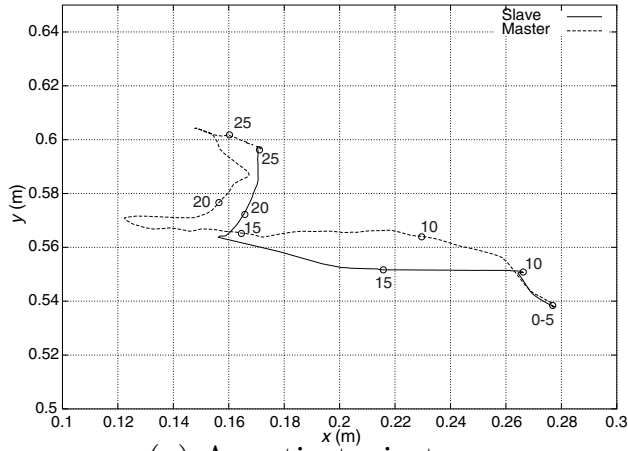

(a) Arm tip trajectory

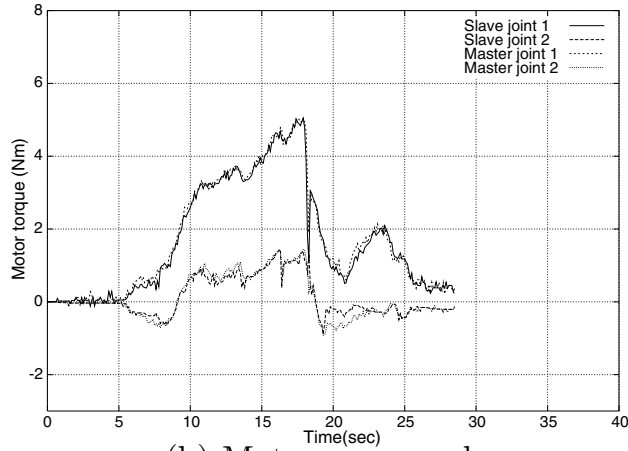

(b) Motor command

Figure 19: 2-DOF peg-in-hole experiment results without visual information (Type B controller).

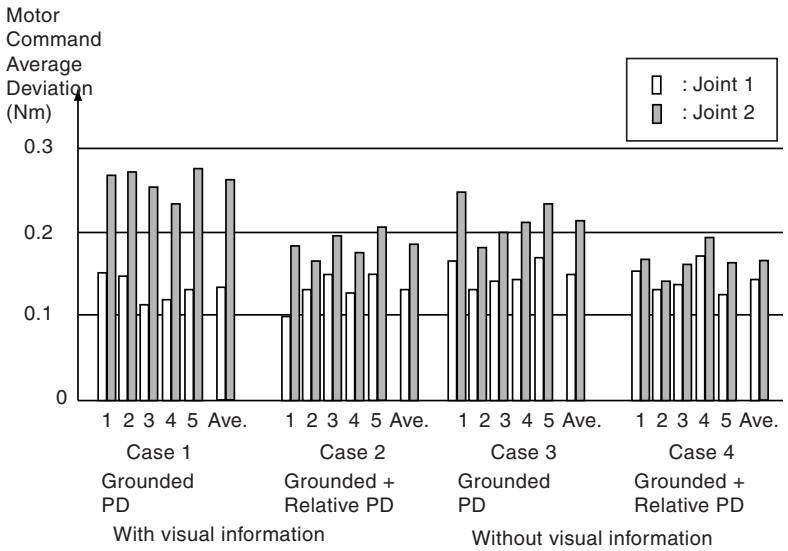

Figure 20: 2-DOF experimental results. Motor command average deviation between master and slave (5 time trials and average values) are illustrated. The deviation is smaller with Type B controller than Type A controller. 
the relative damping, the system maintained stability with attenuated grounded damping. Second, performance evaluation was conducted using a hybrid matrix. As a result, we showed that introducing relative damping into a PD-based controller improved the performance of the teleoperator. Third, to evaluate teleoperator performance, we conducted 1-DOF simulations, 1-DOF experiments and 2DOF peg-in-hole experiments. The teleoperator performance was evaluated using these simulations and experiments. These results showed performance improvement with a PD controller with relative damping.

With regard to the consistency of the evaluation with $\boldsymbol{H}$ and simulation/experimental results, the validity of performance evaluation with the $\boldsymbol{H}$ matrix was demonstrated. By iterating the stable gain setting and performance evaluation using the $\boldsymbol{H}$ matrix as shown in this paper, a controller design that guarantees both stability and performance has been achieved.

The design methodology of optimum gain balance of relative and grounded damping, performance comparison with other control law, such as a passivity based approach, and stability analysis with time-variant delay will be investigated in future research.

\section{ACKNOWLEDGEMENT}

The authors would like to thank Dr. K. Tsuchiya of Doshisha University, Kyoto, Japan and Dr. Y. Yokokohji of Kobe University, Kobe, Japan for their helpful discussions.

\section{REFERENCES}

[1] R. J. Anderson and M. W. Spong, "Bilateral Control of Teleoperators with Time Delay," IEEE Trans. Autom. Control, vol. 34, no. 5, pp. 494-501, 1989.

[2] E. Folke Bolinder, "Survey of Some Properties of Linear Networks," IRE Trans. Circuit Theory, pp. 70-78, 1957.

[3] R. C. Dorf and J. A. Svoboda, Introduction to Electric Circuits. 5th ed. John Wiley and Sons, 2001.

[4] B. Hannaford, " A Design Framework for Teleoperators with Kinesthetic Feedback", IEEE Trans. Robot. Autom., vol. 5, no. 4, pp. 426-434, 1989.

[5] T. Imaida, Y. Yokokohji, T. Doi, M. Oda, T. Yoshikawa, "Ground-Space Bilateral Teleoperation of ETS-VII Robot Arm by Direct Bilateral Coupling under 7-sec Time Delay Condition," IEEE Trans. Robot. Autom., vol. 20, no. 3, pp. 499-511, 2004.

[6] H. Kawada, T. Namerikawa, "Bilateral Control of Nonlinear Teleoperation with Time Varying Communication Delays" Proceedings, American Control Conference, pp. 189-194, 2008. 
[7] D. A. Lawrence, "Stability and Transparency in Bilateral Teleoperation," IEEE Trans. Robot. Autom., vol. 9, no. 5, pp. 624-637, 1993.

[8] D. Lee and M. W. Spong, "Passive Bilateral Teleoperation with Constant Time Delay," IEEE Trans. Robotics, vol. 22, no. 2, pp. 269-281, 2006.

[9] G. M. H. Leung, Bruce A. Francis, and Jacob Apkarian, "Bilateral controller for teleoperators with time delay via $\mu$-synthesis," IEEE Trans. Robot. Autom., vol. 11, no. 1, pp. 105-116, 1995.

[10] F. B. Llewellyn, "Some Fundamental Properties of Transmission Systems," Proc. IRE, vol. 40, pp. 271-283, 1952 .

[11] Y .Murotsu, K .Senda, A .Mitsuya, K .Yamane, T .Nunohara "Theoretical and experimental Studies for Continuous Path Control of Flexible Manipulator Mounted on a Free-Flying Space Robot," Proceedings, AIAA Guidance, Navigation and Control Conference AIAA-93-3863, pp. 1458-1471, 1993.

[12] G. Niemeyer and J. J. E. Slotine, "Stable Adaptive Teleoperation," IEEE J. of Ocean. Eng., vol. 16, no. 1, pp. 152-162, 1991.

[13] G. Niemeyer and J. J. E. Slotine, "Towards Force-Reflecting Teleoperation Over the Internet," in Proc. IEEE Int. Conf. Robotics and Automation pp. 1909-1915, 1998.

[14] G. Niemeyer and J. J. E. Slotine, "Telemanipulation with Time Delays," Int. J. of Robotics Res., vol. 23, no. 9, pp. 873-890, 2004.

[15] E. Nuno, R. Ortega, N. Barabanov, and L. Basanez, "A Globally Stable PD Controller for Bilateral Teleoperators," IEEE Trans. Robot., vol. 24, no. 3, pp. 753-758, 2008.

[16] E. Nuno, R. Ortega, and M. Spong, "Position Tracking for Non-linear Teleoperators with Variable Time Delay," Int. J. Robitics Res., vol. 28, no. 7, pp. 895-910, 2009.

[17] E. Nuno, L. Basanez, and M. Prada, "Asymptotic Stability of Teleoperators with Variable TimeDelays," Proceedings, IEEE Int. Conference on Robotics and Automation, pp. 4332-4337, 2009.

[18] E. Nuno, L. Basanez, and R. Ortega, "Passivity-based control for bilateral teleoperation: A tutorial," Automatica, vol. 47, pp. 485-495, 2011.

[19] R. Oboe and P. Fiorini, "A Design and Control Environment for Internet-Based Telerobotics," Int. J. Robotics Res., vol. 17, no. 4, pp. 433-449, 1998.

[20] G. Raju, G. Verghese, T. Sheridan, "Design Issues in 2-port Network Models of Bilateral Remote Manipulation," Proceedings, IEEE Int. Conference on Robotics and Automation, pp. 1316-1321, 1989.

[21] G. Sankaranarayanan, B. Hannaford, "Experimental Comparison of Internet Haptic Collaboration with Time-Delay Compensation Techniques" Proceedings, IEEE Int. Conference on Robotics and Automation, pp. 206-211, 2008. 
[22] C. Seo, J-P. Kim, J. Kim, H. Ahn, J. Ryu, "Robustly stable bilateral teleoperation under timevarying delays and data losses: an energy-bounding approach" Journal of Mechanical Science and Technology, Vol. 25, Issue. 8, pp. 2089-2100, 2011.

[23] T. Sheridan, "Space Teleoperation Through Time Delay: Review and Prognosis," IEEE Trans. Robot. Autom., vol. 9, no. 5, pp. 592-606, 1993.

\section{Appendix A. Performance measurement of asymmetrical teleop- erator using a hybrid matrix}

When designing an asymmetrical teleoperator, $(27) \sim(30)$ can be applied, but (36) does not hold true. This means, not only $\boldsymbol{H}$ but also $\boldsymbol{G}$ has to be considered to evaluate the performance under the 4 constraint conditions shown in Table 1. In order to evaluate $\boldsymbol{H}$ and $\boldsymbol{G}$, we have to consider no fewer than 8 elements, a complicated procedure. However, performance evaluation can be simplified and can be judged with only the $\boldsymbol{H}$ matrix under the following conditions.

Assume the asymmetrical teleoperator illustrated in Fig. 21 whose position scaling is $n$ and force scaling is $k$.

From the meaning of the scaling factor, $\boldsymbol{H}$ and $\boldsymbol{G}$ for the ideal responses are:

$$
\boldsymbol{H}_{\text {ideal }}=\left[\begin{array}{ll}
0 & k \\
-1 / n & 0
\end{array}\right], \quad \boldsymbol{G}_{\text {ideal }}=\left[\begin{array}{ll}
0 & -n \\
1 / k & 0
\end{array}\right] .
$$

If we set the gain and arm dynamics according to scaling factor $k$ and $n$

$$
\left[\begin{array}{l}
m_{m} \\
b_{m} \\
D_{1 m} \\
D_{2 m} \\
K_{m}
\end{array}\right]=\frac{k}{n}\left[\begin{array}{l}
m_{s} \\
b_{s} \\
D_{1 s} \\
D_{2 s} \\
K_{s}
\end{array}\right],
$$

the impedance matrix is calculated by

$$
\boldsymbol{Z}=\left[\begin{array}{ll}
\frac{k}{n}\left(m_{s} s+b_{s}+D_{1 s}+\frac{K_{s}}{s}\right) & k K_{s} e^{s T_{2}} / s \\
\frac{1}{n} K_{s} e^{s T_{1}} / s & m_{s} s+b_{s}+D_{1 s}+\frac{K_{s}}{s}
\end{array}\right]
$$

and results in

$$
\Delta H=\frac{k}{n} .
$$


Here, $\Delta H$ is constant for any $\omega$. Considering (33), the evaluation with $\boldsymbol{H}$ has the same meaning as that with $\boldsymbol{G}$. Therefore, when we set the gain and arm dynamics according to (38), asymmetrical teleoperator performance under the 4 constraint conditions (master free / fixed, slave free / fixed) can be evaluated by either the $\boldsymbol{H}$ or the $\boldsymbol{G}$ matrix.

\section{Appendix B. Simulation on other conditions}

We conducted a 1-DOF simulation with a rigid wall. The slave environment is a stiff elastic wall $\left(C_{w}=10000 \mathrm{~N} / \mathrm{m}\right)$. An operator force with $1 \mathrm{~N}$ is inputted to the master arm for $10 \mathrm{~s}$. Case 5 is a $\mathrm{PD}$ controller with grounded damping (Type A controller) and Case 6 is a PD controller with grounded and relative damping (Type B controller). The gain setting is the same as section 3.2. Fig. 22 shows the simulation results. Fig. 22 is similar to Fig. 8. No significant difference can be seen.

In Fig. 8, significant oscillation can be seen. In the simulation of Fig. 8, we set the damping of the operator dynamics and slave side environment to be 0 to demonstrate clear and simple teleoperator performance. In practice these conditions are not realistic. Here, we conducted a 1-DOF simulation with more realistic conditions. We added damping to both operator dynamics and environment dynamics. Fig. 23 shows the simulation results. The oscillation is significantly less than Fig. 8. Therefore, in a realistic condition with damping in the operator and environment sides, the oscillation, as seen in Fig. 8 , does not occur, and the operator can conduct the teleoperation.

\section{Appendix C. The passivity of a 2-DOF Teleoperator}

In this section, we see the stability of a 2-DOF teleoperator is derived from utilization of the passivity of the 1-DOF teleoperator discussed in the text. Fig. 24 shows a block diagram of the 2-DOF master-slave system. In Fig. 24, $M_{i i}$ is effective inertia, $M_{i j}$ is coupling inertia, $h_{i j j}$ is the centrifugal acceleration coefficient and $h_{i j k}(j \neq k)$ is the coriolis acceleration coefficient of each arm. The 1-DOF teleoperator analyzed in the text is shown in the box with a dashed line. The dynamics of the coupling between links 1 and 2 are shown within the box with a dotted line. From the passivity of a 1-DOF teleoperator, the arm coupling dynamics and the slave side environment, we obtain the following equations:

$$
\begin{gathered}
\int_{0}^{\infty}\left(\tau_{m 1}^{\prime}(t) \dot{\theta_{m 1}}(t)-\tau_{s 1}^{\prime}(t) \dot{\theta_{s 1}}(t)\right) d t \geq 0 \\
\int_{0}^{\infty}\left(\tau_{m 2}^{\prime}(t) \dot{\theta_{m 2}} \cdot(t)-\tau_{s 2}^{\prime}(t) \dot{\theta_{s 2}}(t)\right) d t \geq 0 \\
\int_{0}^{\infty}\left(\tau_{m 1}^{\prime}(t) \theta_{m 1}^{\dot{2}}(t)+\tau_{m 2}^{\prime}(t) \theta_{m 2}^{\cdot}(t)-\tau_{m 1}^{\prime \prime}(t) \theta_{m 1}^{\cdot}(t)-\tau_{m 2}^{\prime \prime}(t) \theta_{m 2}(t)\right) d t \geq 0 \\
\int_{0}^{\infty}\left(\tau_{s 1}^{\prime}(t) \dot{\theta_{s 1}}(t)+\tau_{s 2}^{\prime}(t) \dot{\theta_{s 2}}(t)-\tau_{s 1}^{\prime \prime}(t) \dot{\theta_{s 1}}(t)-\tau_{s 2}^{\prime \prime}(t) \dot{\theta_{s 2}}(t)\right) d t \geq 0
\end{gathered}
$$




$$
\int_{0}^{t}\left(\tau_{s 1}^{\prime \prime}(t) \dot{\theta_{s 1}}(t)+\tau_{s 2}^{\prime \prime}(t) \dot{\theta_{s 2}}(t)\right) d t \geq 0 .
$$

We used the definition of passivity in the $n$-port network in Anderson and Spong [1]. From (41) $\sim(45)$, we derive

$$
\int_{0}^{t}\left(\tau_{m 1}^{\prime \prime}(t) \theta_{m 1}^{\cdot}(t)+\tau_{m 2}^{\prime \prime}(t) \theta_{m 2}^{\cdot}(t)\right) d t \geq 0 .
$$

Equation (46) indicates the 2-DOF master-slave system is passive with regard to input by the operator. Thus, we come to the conclusion that 2-DOF master slave systems are stable. 


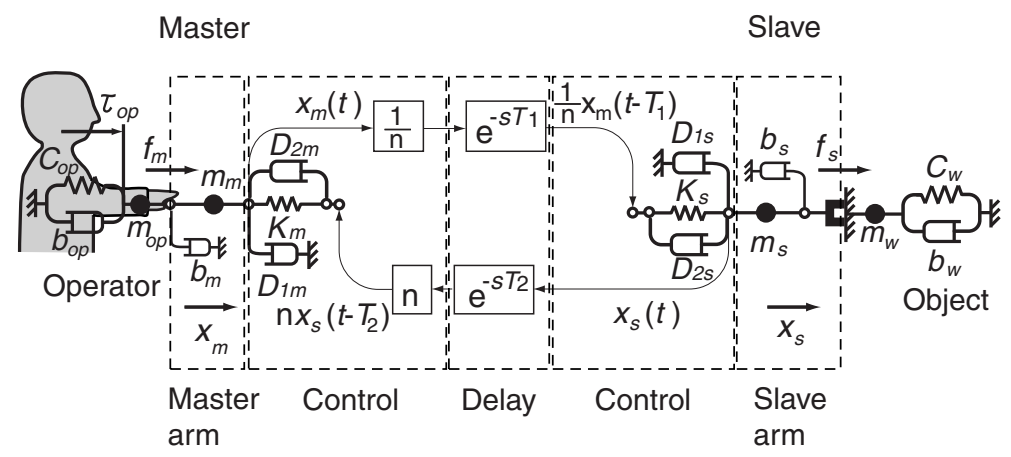

Figure 21: Scaled bilateral master slave system with PD controller.

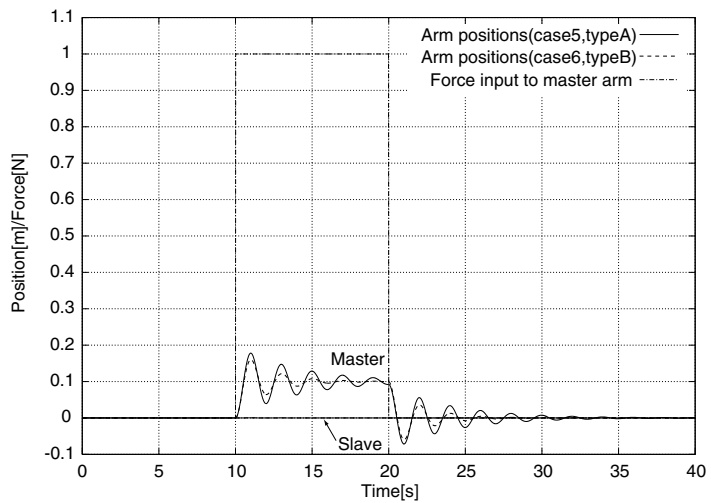

(a)

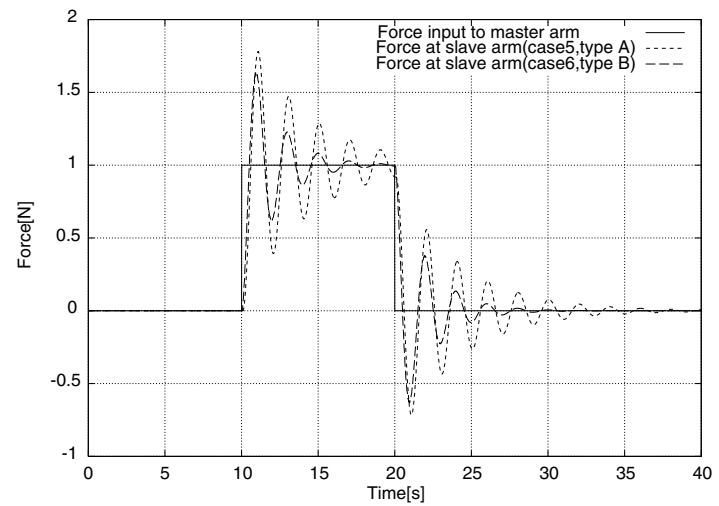

(b)

Figure 22: Simulation results of rigid wall contact $\left(C_{w}=10000 \mathrm{~N} / \mathrm{m}\right)$.

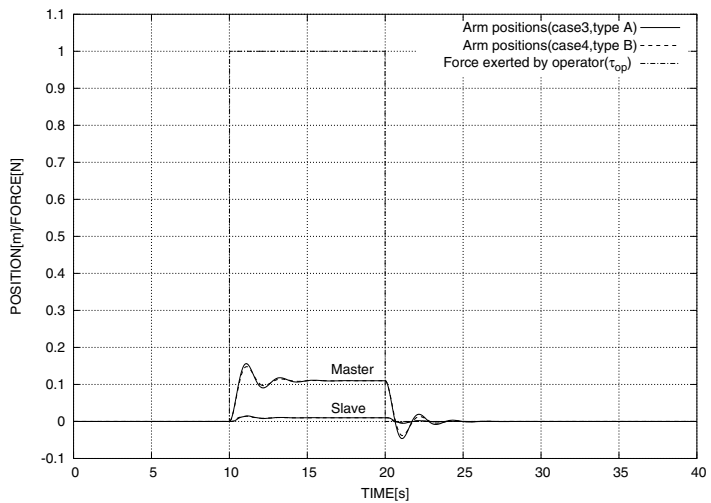

(a)

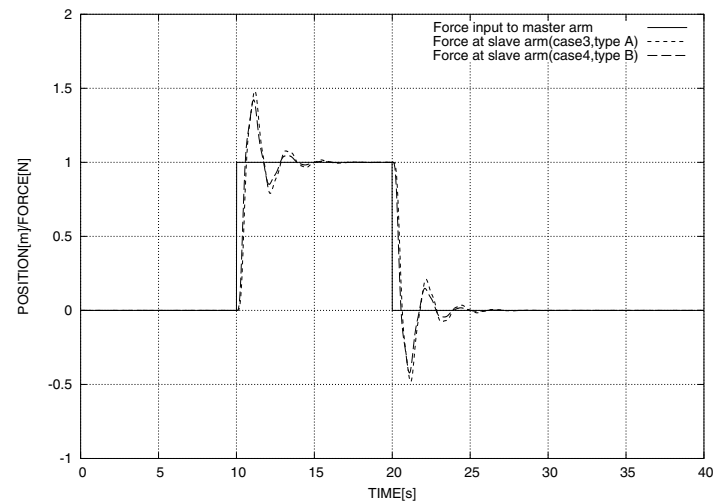

(b)

Figure 23: Simulation results of operator dynamics with damping $\left(C_{w}=100\right.$ $\left.\mathrm{N} / \mathrm{m}, b_{w}=1 \mathrm{~N} \cdot \mathrm{s} / \mathrm{m}, b_{o p}=1 \mathrm{~N} \cdot \mathrm{s} / \mathrm{m}\right)$. 


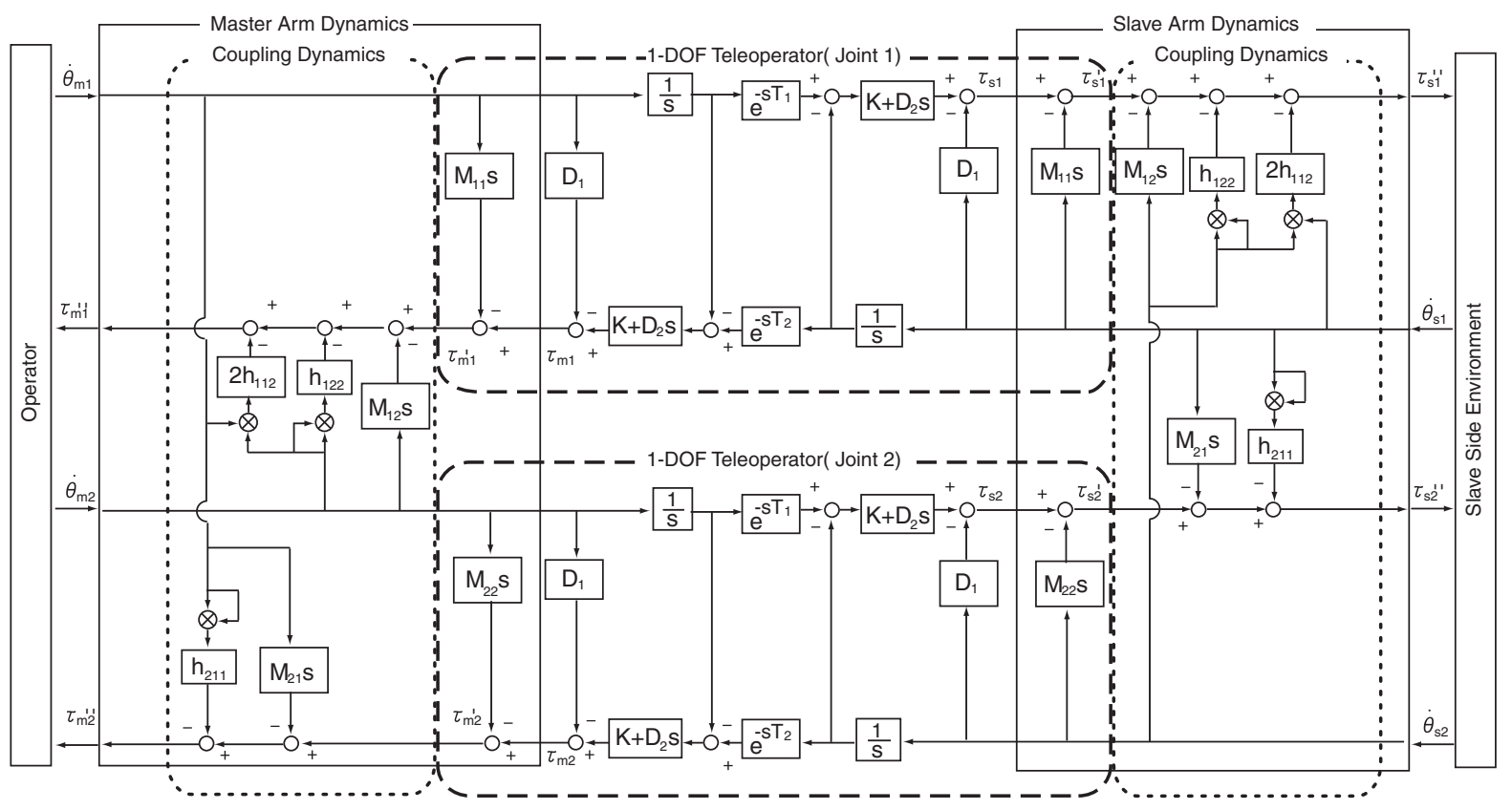

Figure 24: 2-DOF master slave system with PD controller. 


\section{Appendix D. Stability with various time delay conditions}

In the stability analyses, simulations and experiments in the text, we assume $T_{1}=T_{2}$, and they are constant and known delays. From the discussion in sections 2.2 and 2.3 as well as (16) and (24), the stability with other delay conditions is shown in Table 7 .

As shown in the $\left.{ }^{*}\right)$ column in Table 7 , with a type B controller, if the real time delay $T\left(=T_{1}=T_{2}\right)$ is shorter than the delay $T_{e}$ used in the stability derivation, the system stability is maintained as shown in the following.

Assume a stable master slave system under delay $T_{e}$. From (24), we obtain

$$
D_{1}+b_{2} \geq \max _{\omega>0}\left|D_{2} \cos \omega T_{e}-\frac{K T_{e}}{\omega T_{e}} \sin \omega T_{e}\right|-D_{2} .
$$

Let

$$
\begin{gathered}
T_{e}>T \\
\max _{\omega>0}\left|D_{2} \cos \omega T-\frac{K T}{\omega T} \sin \omega T\right|=M_{1} \\
\max _{\omega>0}\left|D_{2} \cos \omega T_{e}-\frac{K T_{e}}{\omega T_{e}} \sin \omega T_{e}\right|=M_{2} .
\end{gathered}
$$

From $D_{2} \cos \omega T-\frac{K T}{\omega T} \sin \omega T=\sqrt{D_{2}^{2}+\left(\frac{K T}{\omega T}\right)^{2}} \cos (\omega T+\alpha)$, we obtain

$$
M_{1}>D_{2}
$$

where

$$
\begin{aligned}
& \cos \alpha=D_{2} / \sqrt{D_{2}{ }^{2}+\left(\frac{K T}{\omega T}\right)^{2}} \\
& \sin \alpha=\frac{K T}{\omega T} / \sqrt{D_{2}{ }^{2}+\left(\frac{K T}{\omega T}\right)^{2}} .
\end{aligned}
$$

Assume $\omega_{0}$ is the value which brings the maximum value of (49), see Fig. 25. Then

$$
\left|D_{2} \cos \omega_{0} T-\frac{K T}{\omega_{0} T} \sin \omega_{0} T\right|=M_{1} .
$$

We introduce $\omega_{1}$ and assume $\omega_{0} T=\omega_{1} T_{e}$, and we have

$$
\begin{aligned}
\left|D_{2} \cos \omega_{1} T_{e}-\frac{K T_{e}}{\omega_{1} T_{e}} \sin \omega_{1} T_{e}\right| & =\left|D_{2} \cos \omega_{0} T-\frac{K T_{e}}{\omega_{0} T} \sin \omega_{0} T\right| \\
& =\left|D_{2} \cos \omega_{0} T-\frac{K T}{\omega_{0} T} \sin \omega_{0} T-\frac{K\left(T_{e}-T\right)}{\omega_{0} T} \sin \omega_{0} T\right|
\end{aligned}
$$

From (51) and (54), $D_{2} \cos \omega_{0} T$ and $-\frac{K T}{\omega_{0} T} \sin \omega_{0} T$ have the same sign. Then, $-\frac{K\left(T_{e}-T\right)}{\omega_{0} T} \sin \omega_{0} T$ has the same sign. Therefore,

$$
\begin{aligned}
\left|D_{2} \cos \omega_{1} T_{e}-\frac{K T_{e}}{\omega_{1} T_{e}} \sin \omega_{1} T_{e}\right| & =\left|D_{2} \cos \omega_{0} T-\frac{K T}{\omega_{0} T} \sin \omega_{0} T\right|+\left|\frac{K\left(T_{e}-T\right)}{\omega_{0} T} \sin \omega_{0} T\right| \\
& >\left|D_{2} \cos \omega_{0} T-\frac{K T}{\omega_{0} T} \sin \omega_{0} T\right|=M_{1}
\end{aligned}
$$

From (50) and inequality (58), we obtain

$$
M_{2}>M_{1}
$$


Table 7: Stability of Type A and Type B controller with various time delay conditions

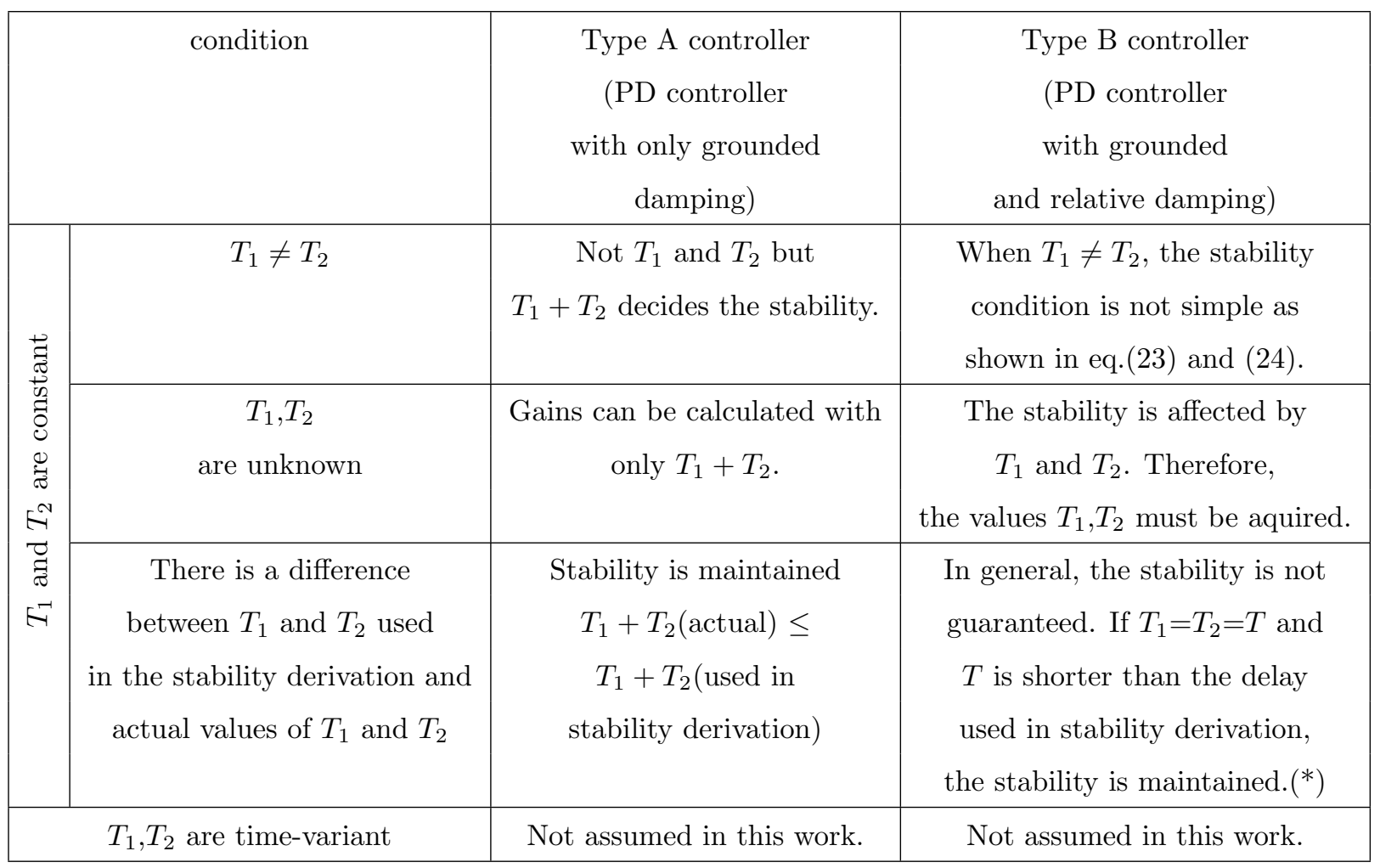

(*) Derivation is shown in Appnedix.D.

From (47), (49), (50) and (59), we have

$$
D_{1}+b_{2}>\max _{\omega>0}\left|D_{2} \cos \omega T-\frac{K T}{\omega T} \sin \omega T\right|-D_{2} .
$$

Therefore, we conclude that the system is stable even if the real delay $T$ is shorter than the delay $T_{e}$ used in the stability derivation. 


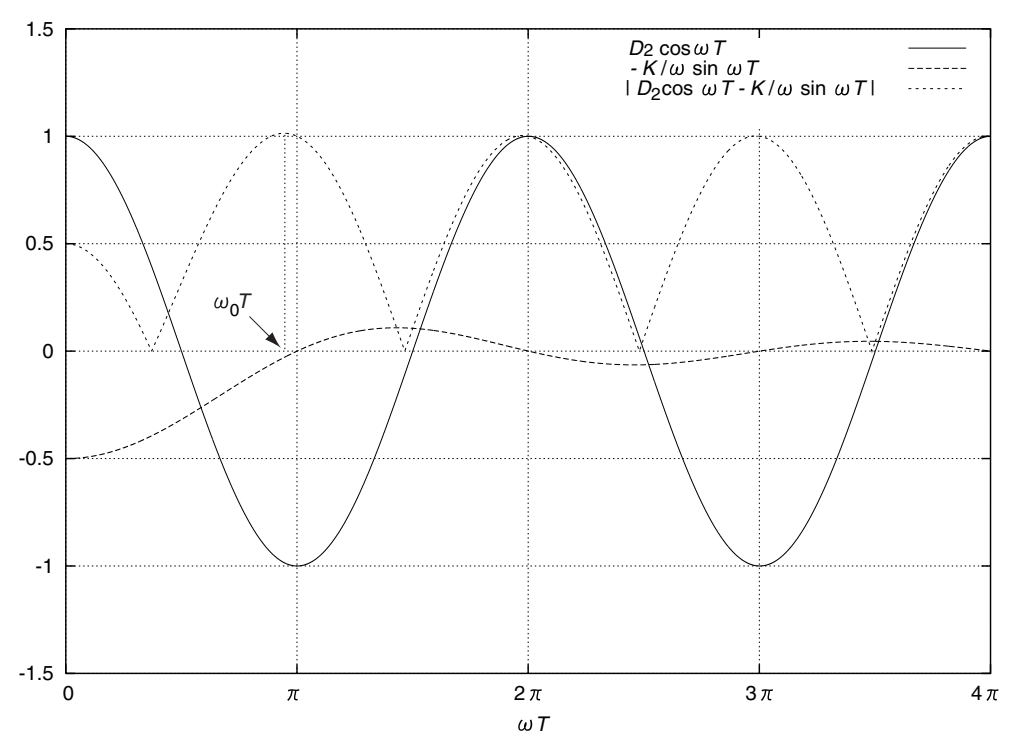

Figure 25: Numerical calculation results. The elements of stability condition (24) are shown. $K=10 \mathrm{~N} / \mathrm{m}, D_{2}=1.0 \mathrm{~N} \cdot \mathrm{s} / \mathrm{m}, T=0.05 \mathrm{~s}$. 